\title{
Guantánamo, neo-estructura atípica del Caribe Norte
}

\author{
Mario Octavio Cotilla Rodríguez¹, macot@ucm.es; Diego Córdoba Barba1', dcordoba@ \\ ucm.es
}

\begin{abstract}
RESUMEN
Este trabajo es un estudio morfotectónico de la provincia de Guantánamo, en Cuba Oriental. Este territorio está en la parte meridional de la placa de Norteamérica y se diferencia, principalmente, por la actividad sísmica y el mecanismo de foco de los segmentos adyacentes de Santiago de Cuba, en la misma placa, y del Norte de Haití, en la placa del Caribe. En este marco tectónico cubano hay una celda geodinámica (C2) con movimiento horario, que incluye 8 bloques activos, 2 zonas de deformación costeras arqueadas y cóncavas ( $\mathrm{Cc} 1=$ Baconao-Bahía de Guantánamo y Cc2= Maisí), 2 zonas de articulación de morfoestructuras de $2^{\circ}$ orden (IV y V), un escalón morfoestructural S-N (Punta Caleta-Punta del Fraile) y 3 zonas sísmicas (Baracoa, Guantánamo y Maisí), pero con menor nivel que en Santiago de Cuba y en Haití. El principal sistema de fallas lo constituyen 4 elementos activos de categoría: 1) Primero: falla Oriente (E-O, la más importante); 2) Segundo: falla Nortecubana; 3) Tercera A: falla Baconao; y 4) Tercera B: falla Purial. Las 3 últimas fallas tienen dirección NO y NNO. Se ha determinado, por primera vez, un tensor de esfuerzos (T1-2) NNE de tipo transpresivo para el segmento de Baconao-Guantánamo. Desde el punto de vista neotectónico, la zona es mucho menos activa que los territorios adyacentes de: 1) la Sierra Maestra y la Cuenca del Cauto, en Cuba Oriental; y 2) el N de Haití.
\end{abstract}

Palabras clave: Caribe Norte, Cuba, Guantánamo, morfotectónica.

\section{Guantánamo atypical neo-structure of North Caribbean}

\begin{abstract}
The work is a morphotectonic study of Guantánamo Province in Eastern Cuba. This territory is in the southern part of the North American plate. It differs mainly by seismic activity and the focal mechanisms of the adjacent segments of Santiago de Cuba, on the same plate, and the $\mathrm{N}$ of Haití, in the Caribbean plate. In this Cuban tectonic framework there is: a Geodynamic cell (C2) with clockwise movement, which includes 8 active blocks, 2 zones of coastal deformation arched and concave $(\mathrm{Cc} 1=$ Baconao-Bahía de Guantánamo and Cc2= Maisí), 2 morphostructural articulation areas of $2^{\text {nd }}$ order (IV and V), a S-N morphostructural escarpment (Punta Caleta-Punta del Fraile), and 3 seismic zones (Baracoa, Guantánamo and Maisí), but with lower level than in Santiago de Cuba and Haití. The main fault system is constituted by 4 active elements of 3 categories: 1) First: Oriente fault (E-W, the most important); 2) Second: Nortecubana fault; 3) Third A: Baconao fault; and 4) Third B: Purial fault. The 3 last elements have NW and NNW strikes. It has been determined, for the first time, a NNE tensor of efforts (T1-2) of transpressive type for the Baconao-Guantánamo segment. From the neotectonic point of view, the Guantánamo area is much less active than the adjacent territories of: 1) the Sierra Maestra and the Cauto basin, in Eastern Cuba; and 2) the $\mathrm{N}$ of Haití.
\end{abstract}

Keywords: North Caribbean, Cuba, Guantánamo, morphotectonics.

Recibido el 27 de julio de 2015, aceptado el 28 de noviembre de 2015.

1 Universidad Complutense de Madrid, Facultad de Ciencias Físicas, Departamento de Física de la Tierra, Astronomía y Astrofísica I. Ciudad Universitaria S/N, 28040 Madrid, España. 


\section{INTRODUCCIÓN}

Cuba es un archipiélago $\left(110.922 \mathrm{~km}^{2}\right)$ del Caribe con la mayor isla del Arco de Las Antillas Mayores (Figura 1A). Su extensión es de $\sim 1.260 \mathrm{~km}$ (Cabo de San AntonioPunta de Quemado (Fig. 1)); mientras que sus costas miden en total $\sim 5.750 \mathrm{~km}(\sim 3.210$ $\mathrm{km}$ la $\mathrm{N}$ y $\sim 2.540 \mathrm{~km}$ la S). La plataforma insular $\left(\sim 68.000 \mathrm{~km}^{2}\right)$ le rodea con un ancho de $-10 \mathrm{~m}$ a $-55 \mathrm{~m}$ donde predominan las llanuras (abrasivas y abrasivoacumulativas); también hay algunas formas sub-aéreas (escarpes, cauces y depresiones de diferente geometría). El talud insular es un escalón estructural y tectónico de $\sim-5 \mathrm{~km}$ de profundidad que limita con las zonas más profundas (fosas y depresiones oceánicas). Para la investigación del territorio cubano se ha seleccionado la parte oriental, denominada Cuba Oriental, que posee un área de $\sim 45.000 \mathrm{~km}^{2}$.

Cuba Oriental (Fig. 1B) se diferencia muy bien del resto de la isla por su relieve montañoso $(\sim 90 \%)$ y la inmediata cercanía a una fosa oceánica, Oriente $(\sim-6.800 \mathrm{~m})$. Cuba Oriental tiene un área de $\sim 27.000$ $\mathrm{km}^{2}$ y las dimensiones lineales $(\mathrm{km})$ de $\mathrm{O}$ a E son: A) Cabo Cruz-Punta de Quemado= 370; B) Cabo Cruz-Pilón= 40; C) PilónUvero $=25$; D) Uvero-Caletón Blanco $=108$; E) Caletón Blanco-Baconao= 582; F) PilónBahía de Guantánamo= 217; G) Bahía de Guantánamo-Punta de Quemado=105; H) Punta Caleta-Boca del Yumurí= 266; e I) Punta de Quemado-Punta Caleta $=15$. Hay significativas diferencias hipsométricas, morfológicas, litológicas y tectónicas que consecuentemente afectan a la red fluvial y las costas (Figs. 1A y C). Se indican 2 ejes de simetría: A) E-O $=323 \mathrm{~km}$ y B) $\mathrm{N}-\mathrm{S}=126 \mathrm{~km}$ (Fig. 2A), y entre ellos hay un alineamiento transversal SE-NO, denominado Purial $(\sim 100 \mathrm{~km})$ (Fig. 3B). También la sismicidad (cantidad de terremotos y sus magnitudes) permite valorar muy bien las diferencias del territorio (Fig. 2B).

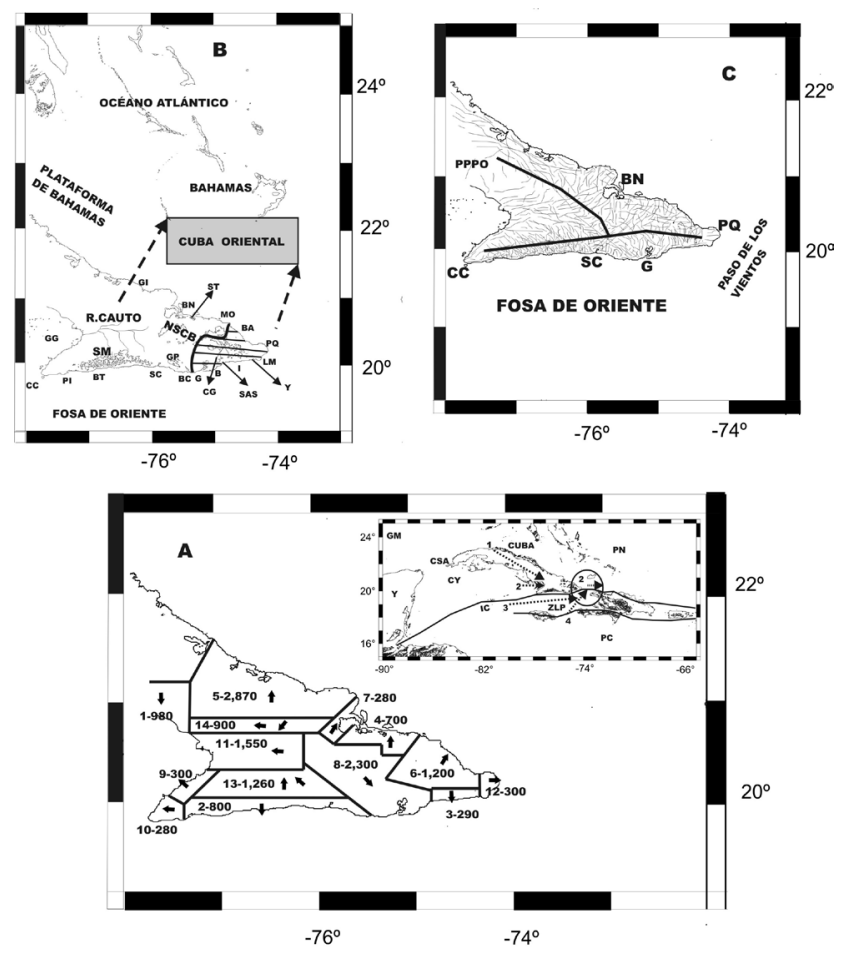

Fig. 1. Características de Cuba Oriental.

Fig. 1. Characteristics of Eastern Cuba. 
A) Regionalización del drenaje superficial. Aparecen: 1) sentido del drenaje (flecha negra); 2) zonas de drenaje ( $1=\mathrm{S}$ de Camagüey / N-S, 2= Sur de Sierra Maestra $/ \mathrm{N}-\mathrm{S}, 3=$ Sur de Sierra de Purial / N-S, 4= Bahía Nipe-Sagua / S-N, 5= Gibara-Nuevitas / S-N, 6= Moa-Baracoa / NE, $7=$ Bahía de Nipe $/$ NE, $8=$ CautoGuantánamo / SE, 9= Manzanillo / NO, $10=$ Cabo Cruz $/$ E-O, $11=$ Cauto $/$ E-O, 12= Maisí $/$ O-E, 13= Norte de la Sierra Maestra / S-N - NO, 14= San Germán ( E-O - SO); 3) área $\left(\mathrm{km}^{2}\right)$ de la zona de drenaje (10-200); 4) recuadro del archipiélago de Cuba: 1) dirección de las estructuras principales (flecha negra: $1=$ Cuba Central, 2= Cuba Oriental-Norte de Haití, 3= Fosa de Oriente, 4= Paso de los Vientos); 2) localidades ( $\mathrm{CSA}=$ Cabo de San Antonio, CY= Cuenca de Yucatán, $\mathrm{GM}=$ Golfo de México, $\mathrm{IC}=$ Islas Caimán, $\mathrm{PC}=$ Placa Caribe, $\mathrm{PN}=$ Placa de Norteamérica, $Y=$ Yucatán, $\mathrm{ZLP}=$ Zona Límite de Placas).
B) Localidades y principales elementos del relieve.

Aparecen: 1) localidades: $\mathrm{B}=$ Baitiquirí, $\mathrm{BA}=$ Baracoa, $\mathrm{BC}=$ Baconao, $\mathrm{BN}=$ Bahía de Nipe, BT= Boca del Toro, $\mathrm{CC}=$ Cabo Cruz, $\mathrm{CG}=$ Cuenca de Guantánamo, $\mathrm{G}=$ Guantánamo, $\mathrm{GG}=$ Golfo de Guacanayabo, GI= Gibara, $\mathrm{GP}=$ Gran Piedra, $\mathrm{I}=$ Imías, $\mathrm{LM}=\mathrm{La}$ Maqueyera, $\mathrm{MO}=\mathrm{Moa}, \mathrm{NSCB}=$ Grupo Nipe-Sagua-Cristal-Baracoa-Purial, $\mathrm{PI}=$ Pilón, $\mathrm{PQ}=$ Punta de Quemado, $\mathrm{R}$. Cauto $=$ Río Cauto, $\mathrm{SC}=$ Santiago de Cuba, SAS= San Antonio del Sur, SM= Sierra Maestra, $Y=$ Yana; 2) provincia administrativa Guantánamo (área con rayas inclinadas).

c) Esquema de alineaciones de la red fluvial. Aparece: 1) localidades (BN= Bahía de Nipe, $\mathrm{CC}=$ Cabo Cruz, $\mathrm{G}=$ Guantánamo, $\mathrm{PQ}=$ Punta de Quemado, $\mathrm{SC}=$ Santiago de Cuba); 2) alineaciones fluviales; 3) PPPO= Parteaguas Principal de Primer Orden.

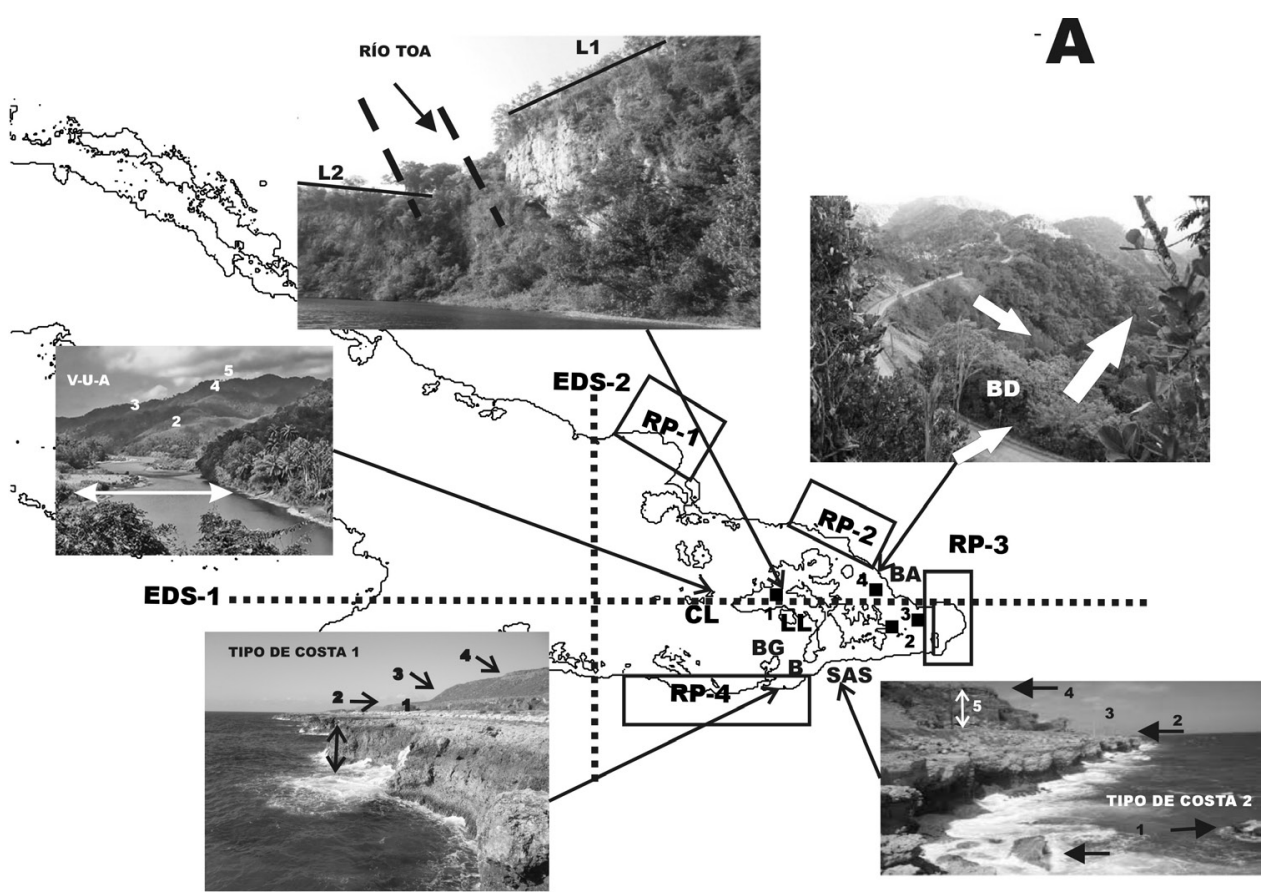

Fig. 2. Características del relieve de Guantánamo.

Fig. 2. Characteristics of Guantánamo relief. 
A) Representación de elementos morfoestructurales de la parte occidental de Guantánamo.

Aparecen: 1) localidades $\quad(B=$ Baitiquirí, $\mathrm{BA}=$ Baracoa, $\mathrm{BG}=$ Bahía de Guantánamo, $\mathrm{CL}=\mathrm{El}$ Clueco, LL= Los Llanos, SAS= San Antonio del Sur); 2) fotos: (A) Baitiquirí (tipo de costa 1. Las flechas indican: $1=1^{\mathrm{a}}$ terraza; 2,3 y $4=$ niveles de planación), B) San Antonio del Sur (tipo de costa 2. Las flechas indican: $1=$ desprendimientos, $2=1^{\mathrm{a}}$ terraza; $3 \mathrm{y}$ $4=$ niveles de planación, $5=$ desnivel), C) montañas de Baracoa (indicación con flecha blanca de las pendientes y desniveles), D) Los Llanos, tramo "V" del río Toa (fracturas transversales del relieve), E) El Clueco, tramo del río Toa (distintos niveles del proceso erosivo: $1,2,3,4) ; 3) \mathrm{EDS}=$ ejes de simetría (1 y 2); 4) región de curvatura cóncava: RP1= Holguín, RP2= Moa, RP3= Maisí, RP4= Santiago-San Antonio del Sur; 5) zona con anomalías fluviales muy significativas (cuadrados negros con números (1)).

Los españoles llegaron a Cuba, presumiblemente, por la costa septentrional de Cuba Oriental en las inmediaciones de Baracoa, en la actual provincia administrativa de Guantánamo (Fig. 1B). Posteriormente, los asentamientos humanos se produjeron desde la Punta de Maisí hacia la parte occidental. La fundación de los pueblos, de nuestro interés a los efectos comparativos, fue la siguiente: Nuestra Señora de la Asunción de Baracoa (actual Baracoa) en el año 1512 (16 años después ocurrió un terremoto), Bayamo en 1513, Santiago de Cuba en 1515, Sagua de Tánamo en 1745 y Guantánamo en 1796 (como ciudad y capital de la provincia ocurrió 304 años después del Descubrimiento de América).

Guantánamo (figs. 1B y C) es una de las 4 provincias administrativas que están en Cuba Oriental (Granma, Holguín y Santiago de Cuba). Entre sus ciudades aparecen:
Baitiquirí, Baracoa, Imías, La Asunción, La Máquina, La Yana, Moa y San Antonio del Sur. Ella tiene las siguientes características: A) área $=\sim 6.200 \mathrm{~km}^{2}$; B) habitantes= $\sim 511.000$; C) relieve= montañoso; D) $\mathrm{h}_{\text {máx }}$ $(\mathrm{m})=\sim 1.200$; E) corrientes fluviales $=\sim 400$; F) amplitud máxima de los movimientos neotectónicos verticales más jóvenes $(\mathrm{m})=$ $\sim 100$; y $\mathrm{G}$ ) pendiente media (m por $\mathrm{km}$ ): G.a) $C C-B=107.8$; y G.b) $B-P Q=45.2$. $E n$ las provincias de Guantánamo y Holguín está el Grupo Montañoso Nipe-SaguaBaracoa-Purial $\left(\sim 9.400 \mathrm{~km}^{2}\right.$ ) (Loma de la Mensura (995 m al S de Mayarí), Mayarí Arriba (751 m), Pico del Toldo (al S de Moa a $1.175 \mathrm{~m}$ ) y Sierra del Purial (Pico El Gato, N de Imías, $1.181 \mathrm{~m})$ ). Destacan en ese marco: 1) el escarpe morfoestructural S-N Punta Caleta-Punta del Fraile (419 m); 2) la disposición y la geometría anómalas de 3 ríos: 2.a) Yumurí (de O a N-S) y su desembocadura en "V" (en las Cuchillas de Baracoa) (Fig. 2B); 2.b) Cajobabo de $\mathrm{O}$ a $\mathrm{N}-\mathrm{S}$; 2.c) Maya de O a NE, hacia la Punta de Maisí.

\section{MÉTODOS}

Los métodos aquí aplicados están recogidos, parcialmente, en diversas publicaciones, entre ellas: AHORNER (1975); ALEKSEEVSKAYA et al. (1977); ASSINOVSKAYA \& SOLOVYEV (1994); BANKWITZ et al. (2003); COTILLA (1993); COTILLA \& CÓRDOBA (2009, 2003); COTILLA et al. (1996); GATINSKY \& RUNDQUIST (2004); GORSHKOV et al. (2000); GRÜNTHAL et al. (1990); RANTSMAN (1979); y ZHIDKOV et al. (1975). Pero, la exposición de los métodos y sus variantes se encuentran en: COTILLA \& CÓRDOBA (2003) y COTILLA et al. (1996A y B y 1991B y D). Ese conjunto configura una metodología que se ha aplicado, por los autores, en diferentes zonas y regiones con buenos resultados, evitando duplicidades e improvisaciones sin fundamento, para su aplicación en los trabajos de Geofísica. 
Los aspectos principales de la metodología son respetar las etapas de la investigación, atendiendo: 1) al orden y nivel de estudio regional y local; 2) al análisis y la selección, argumentados, de los resultados precedentes; 3) a la comprobación de la base anterior sobre el terreno; 4) a la complementación de la información seleccionada; y 5) a la implementación de los datos y su procesado con un SIG.

Inicialmente utilizamos, como base, un modelo digital del relieve de Cuba Oriental (COTILLA \& CÓRDOBA, 2010D). Este material se incluye, como matriz de base, en el SIG y determinamos: 1) los valores máximos en cuadrículas de $0,1 \mathrm{~cm} \quad \mathrm{x}$ 0,1 cm; 2) 3 conjuntos de iso-líneas de $500 \mathrm{~m}, 1.000 \mathrm{~m}$. y $1.200 \mathrm{~m}$. Además, se incorpora la red fluvial desde el orden 2 al 7 (COTILLA et al., 2003), y se distinguen los ríos de orden 3 y mayores atendiendo a la dirección y al sentido de drenaje. También se ajusta, con varios modelos, la línea de costa. Entonces, es a partir de esas matrices que determinamos los ejes de simetría del territorio, ya mencionados.

\section{CONTEXTO GEOLÓGICO Y TECTÓNICO}

Para la base: 1) geológica y tectónica nos apoyamos en: ACADEMIA DE CIENCIAS DE CUBA \& HUNGRÍA (1981); BLANCO \& PROENZA (1994); BRESZNYÁNSZKY et al. (1983); CALMUS (1986); CAMPOS DUEÑAS (1983); CASE et al. (1984); COBIELLA et al. (1984); COTILLA \& UDÍAS (1999A); DEMETS \& WIGGINGS-GRANDISON (2007); DEMETS et al. (2010, 2000); FLORES et al. (1998); FRANCO (1976); GIUNTA et al. (2006); IOIN et al. (1977); KARTASHOV et al. (1981); LINARES et al. (1986); MANN \& BURKE (1984, 1980); MANN et al. (1995); MOLNAR \& SYKES (1969); MOSSAKOVSKIY et al. (1989); PUBELLIER et al. (2000);
PUSHAROVSKY (1988); QUINTAS \& BLANCO (1993); QUINTAS et al. (1994); SHEIN et al. (1985A, B); y VAN BENTHEN \& GOVERS (2010); 2) sobre la neotectónica se usó:ARSENIEV et al. (1983); BENFORD et al. (2012A, B); CALAIS \& MERCIER DE LEPINAY (1995, 1993, 1991, 1990); COTILLA (1993); COTILLA \& CÓRDOBA (2010D); COTILLA et al. (2003, 1998, 1991C, D); GONZÁLEZ et al. (2003, 1989B); ITURRALDE VINENT (1977); MAKAROV (1987, 1986); MAKAROV \& FORMELL(1989); NÚÑEZ CAMBRA (2001); PÉREZ (1989); ROJASAGRAMONTE et al. (2005); SHEIN et al. (1975); TRIFONOV et al. (1981); 3) de la fosa de Oriente utilizamos: CALAIS \& MERCIER DE LÉPINAY (1991, 1990); COBIELLA (1983); COBIELLA \& RODRÍGUEZ (1986); COTILLA (2011); COTILLA \& CÓRDOBA (2011); COTILLA et al. (1991A, D); GONZÁLEZ et al. (2003); HERNÁNDEZ et al. (1996, 1991, 1990, 1989); y LEROY et al. (2000). Así, Cuba está, desde el punto de vista neotectónico, incluida en la parte meridional de la placa de Norteamérica. En esta posición recibe la influencia directa de la interacción con la placa del Caribe. Esta placa es de tipo intermedio al considerar el rango de las grandes placas (Norteamérica y Suramérica) (Fig. 4A). Ella experimenta un desplazamiento neto al $\mathrm{E}$, con valores de 2-4 cm/año. Específicamente en el sector de Cuba es de $2 \mathrm{~cm} /$ año y $1-2 \mathrm{~cm} /$ año en Jamaica. En el $\mathrm{O}$ del Caribe las placas Cocos y Nazca, pertenecientes al sistema del Pacífico, le subducen; mientras que por el E la subducción no tiene tanta intensidad, pero sí es manifiesta desde Barbados. El límite $\mathrm{N}$ es una combinación de movimiento con sentido izquierdo, con componentes de subducción en Puerto Rico-Islas Vírgenes y el $\mathrm{N}$ de La Española; pero el límite $\mathrm{S}$ es más complejo porque hay 2 tipos de fallas (desplazamiento horizontal y subducción) por la influencia de las placas Suramérica y Nazca. Nuestra atención se dirige a la parte septentrional, donde está Cuba Oriental. 


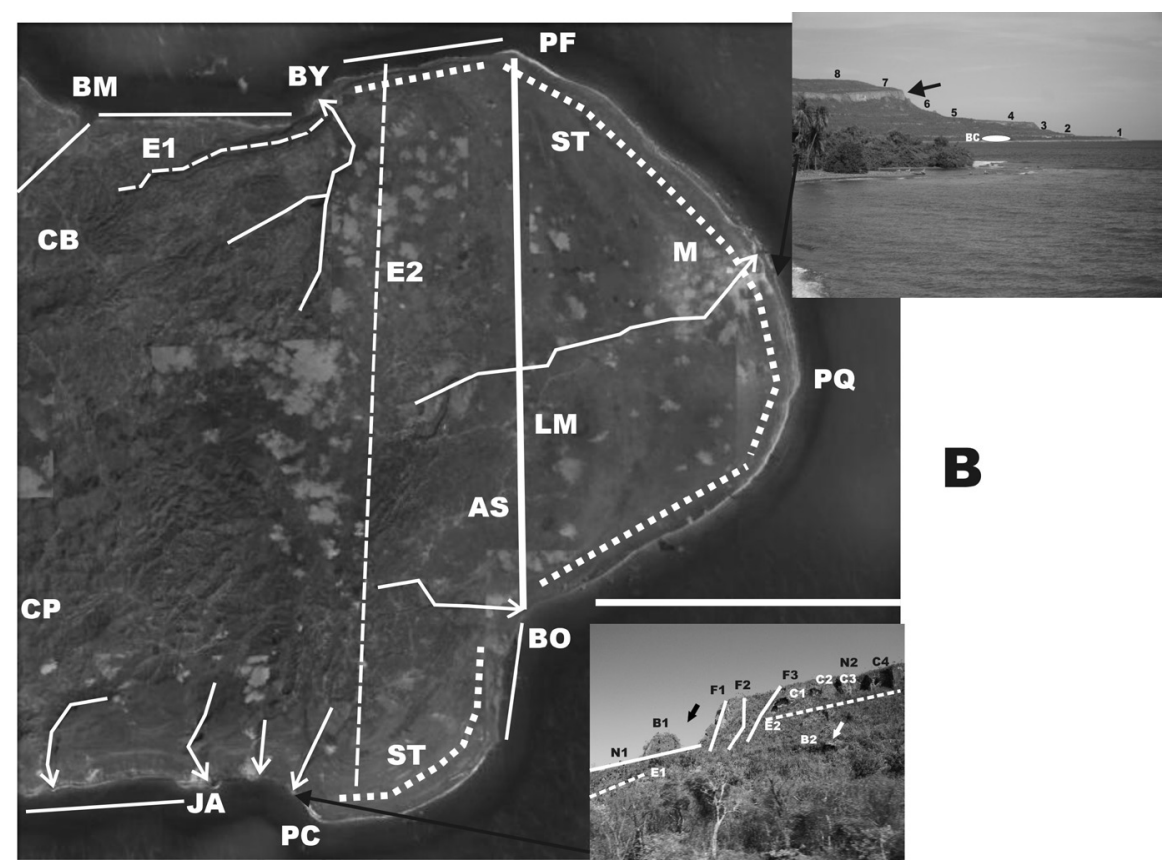

Fig. 2. Características del relieve de Guantánamo.

Fig. 2. Characteristics of Guantánamo relief.

B) Representación de elementos morfoestructurales de la parte oriental de Guantánamo.

Aparecen: 1$)$ localidades $(\mathrm{AS}=$ Asunción, $\mathrm{BM}=$ Bahía de Mata, $\mathrm{BO}=$ Bahía de Ovando, $\mathrm{BY}=$ Boca de Yumurí, $\mathrm{CB}=$ Cuchillas de Baracoa, $\mathrm{CP}=$ Cuchillas de Purial, $\mathrm{JA}=$ Jauco, $\mathrm{LM}=\mathrm{La}$ Máquina, $\mathrm{M}=$ Maisí, $\mathrm{PC}=$ Punta Caleta, $\mathrm{PF}=\mathrm{Punta}$ del Fraile, $\mathrm{PQ}=$ Punta de Quemado); 2) estructuras $(\mathrm{ST}=$ Sistema de terrazas (línea de puntos), E= Escarpe (línea discontinua)); 3) corrientes fluviales con sentido de drenaje; 4) alineaciones (líneas continuas); 4) fotos (A) Maisí (perfil de terrazas, con 8 niveles. La flecha indica una pendiente activa; $\mathrm{BC}=$ Desprendimiento); B) Punta Caleta (1= niveles hipsométricos (N1, N2), 2= bloque caído (B1, B2), 3= escarpes (E1, E2), 3= fracturas (líneas blancas (F1, F2, F3)), 4= cavidades cársticas $(\mathrm{C} 1, \mathrm{C} 2, \mathrm{C} 3, \mathrm{C} 4), 5=$ pendientes activas (flecha negra gruesa)).
La corteza de Cuba se divide en 2 bloques geológicos superpuestos, que se corresponden con diferentes etapas del desarrollo: 1) un cinturón plegado; y 2) un neo-autóctono. Este último comprende la etapa desde el Eoceno Superior (parte alta) hasta la actualidad, donde predominan los movimientos oscilatorios en la vertical. Hay en esa neo-estructura un conjunto de fallas de tipo transcurrente e izquierda (dirección NE-SO), probablemente relacionado con la transpresión a lo largo del margen $\mathrm{N}$ de la placa Caribe. Se reconoce también el desarrollo de cuencas sobre el cinturón deformado (con componentes clástica y carbonatada), pero sin actividad magmática. En la evolución de esas cuencas se ha determinado que hubo 3 etapas, en ciclos de transgresión-regresión y levantamientos. La etapa neo-autóctona, de nuestro interés, comenzó con la actividad de la fosa de Bartlett-Caimán y su sistema de pull-apart, y cuando la convergencia de las placas se trasladó sucesiva y progresivamente hacia el E. Es a través de esa línea de debilidad tectónica donde se localiza el límite de las placas, Caribe-Norteamérica. 
Cuba es un megabloque emergido del $\mathrm{S}$ de la placa Norteamérica (Fig. 4A). Ella es una estructura en ascenso diferencial con 2 unidades neotectónicas, que están asociadas con un conjunto de fallas activas (Fig. 3A). Nuestra atención va, fundamentalmente, a la Unidad Neotectónica Oriental (que equivale aproximadamente al territorio de Cuba Oriental), donde están las fallas activas: Oriente, Nortecubana y Cauto-Nipe (figs. 3A y 4A). Esta unidad neotectónica ha sido considerada un $1^{\text {er }}$ macro-modelo y con esas fallas conforman 3 nudos sismoactivos (NMG0, NMN1 y NMG1) (Fig. 5B). Los nudos son morfoestructuras de $1^{\text {er }}$ orden, al nivel de Cuba. También se ha definido un $2^{\circ}$ modelo (de menor dimensión) que incluye a la falla activa Baconao (Fig. 6A). De esta forma se distinguen 2 celdas: (1) Sierra Maestra y 2) Nipe-Cristal-Baracoa-Purial, y 5 nudos sismoactivos (N-CC, N-CN, N-PM, $\mathrm{N}-\mathrm{BC}$ y N-BO): los 3 antes mencionados y otros 2 relacionados con la falla Baconao.

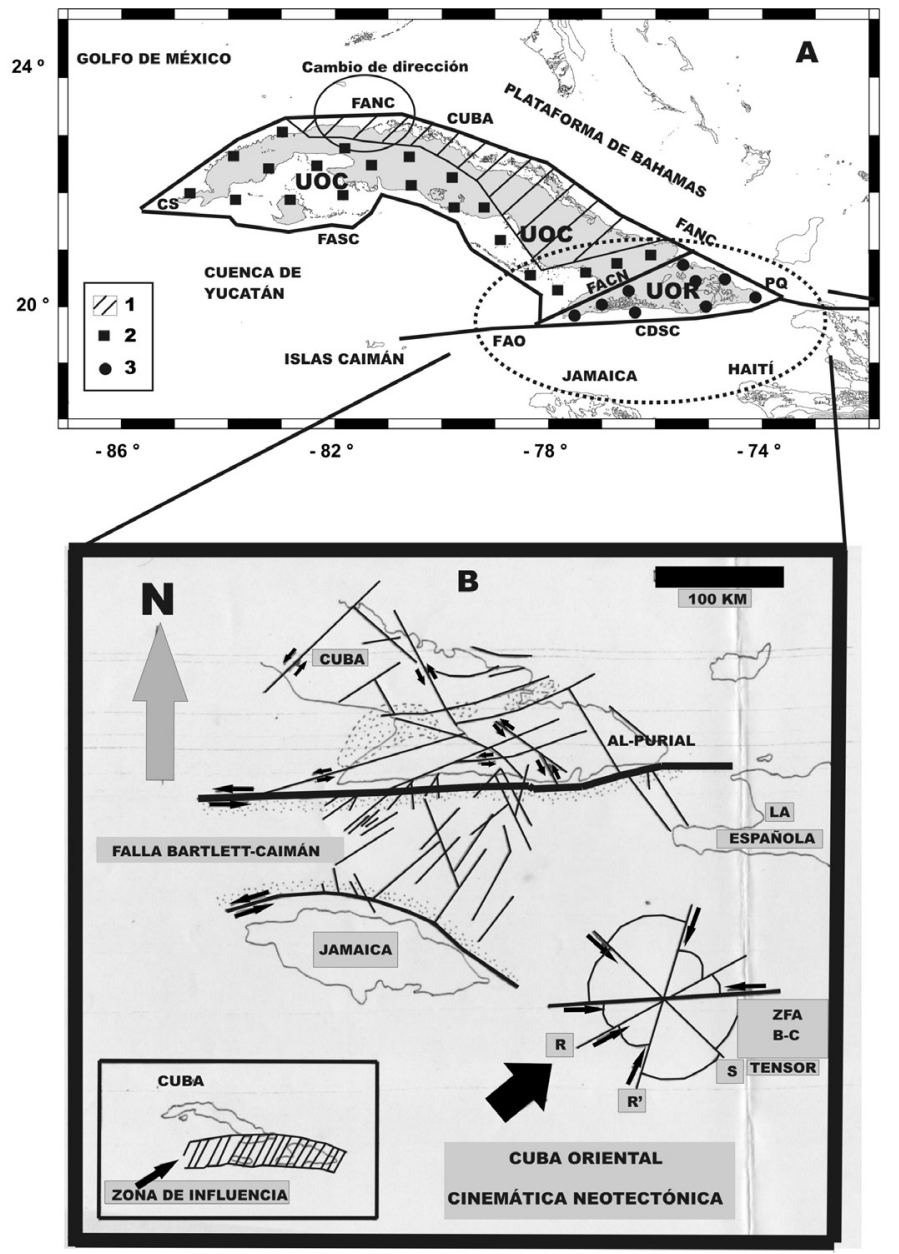

Fig. 3. Neotectónica de Cuba.

Fig. 3. Neotectonics of Cuba. 
A) Mapa neotectónico de Cuba.

Aparecen: 1) unidades neotectónicas (UOC $=$ Occidental y $\mathrm{UOR}=$ Oriental); 2) fallas principales y activas $(\mathrm{FANC}=$ Nortecubana, $\mathrm{FAO}=$ Oriente, $\mathrm{FASC}=$ Surcubana y FACN= Cauto-Nipe); 3) localidades $(\mathrm{Cs}=\mathrm{Cabo}$ de San Antonio y $P Q=$ Punta de Quemado); 4) tipos de corteza $(1=$ continental, $2=$ continental fina y $3=$ intermedia-oceánica); 5) círculo indicando el cambio de dirección en Cuba Occidental.

B) Cinemática neotectónica de Cuba Oriental.

Aparecen: 1) recuadro con la zona de influencia de la interacción entre las placas; 2) fallas (líneas negras) y su sentido de desplazamiento; 3) cuencas (puntos); 4) sistema de Riedel; 4) tensor de esfuerzos (flecha gruesa negra).

Existen varios modelos geodinámicos de placas y microplacas del Caribe Septentrional, pero emplearemos el de los autores. Éste aparece, simplificado, en las figuras 5B y $6 \mathrm{~A}$, y a él se asocia el macromodelo de Cuba Oriental, antes descrito, y la solución para el encuentro de las fallas principales en el Paso de los Vientos, que posteriormente analizaremos.

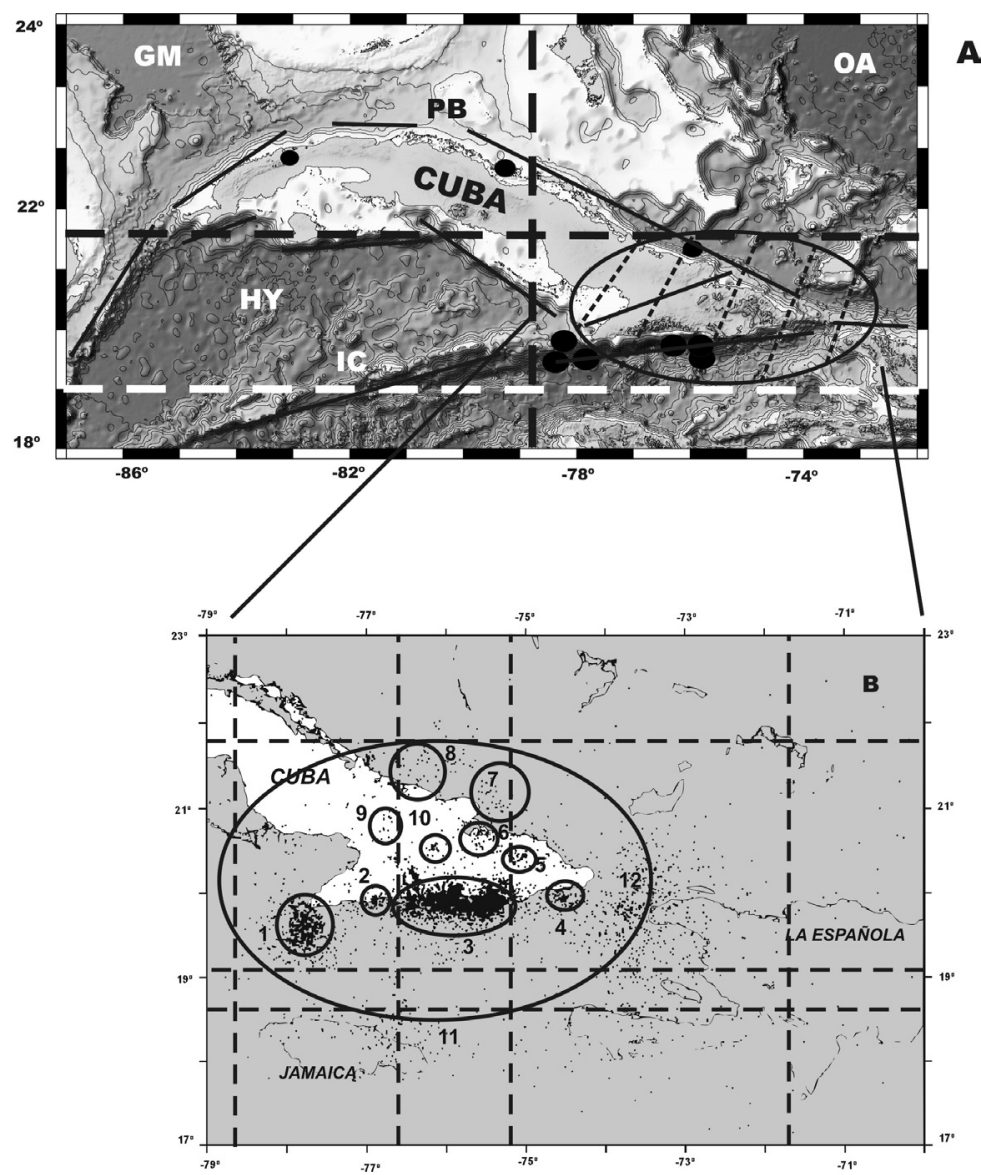

Fig. 4. Actividad sísmica.

Fig. 4. Seismic activity. 
A) Selección de terremotos históricos de Cuba.

Aparecen: 1) áreas geográficas $(\mathrm{GM}=$ Golfo de México, HY= Hoya de Yucatán, $\mathrm{IC}=$ Islas Caimán, $\mathrm{OA}=$ Océano Atlántico, $\mathrm{PB}=$ Plataforma de Bahamas); 2) área de estudio (círculo rayado discontinuo); 3) epicentros de terremotos importantes (círculos negros); 4) alineaciones principales.

B) Sismicidad de Cuba Oriental 19791993.

Aparecen: 1) epicentros (círculos) determinados con la red cubana (> 5 estaciones); 2) agrupamientos de epicentros $(1=$ Cabo Cruz, $2=$ Pilón, $3=$ Pico Turquino-Baconao, 4= BaitiquiríSabana la Mar, 5= Purial-Toa, $6=$ Nipe, $7=$ Bahía de Nipe, $8=$ Nuevitas, 9= Tunas, 10= Cacocum-San Germán, 11= NE de Jamaica y $12=$ NO de Haití).

La figura 3A contiene una versión simplificada del mapa neotectónico de Cuba, donde Cuba Oriental es una estructura diferenciada. Aquí se expone que la corteza es de tipo intermedia-oceánica y puede alcanzar hasta los $30 \mathrm{~km}$. En tanto, con la figura $3 \mathrm{~B}$ hay una representación de los sistemas de fallas y estructuras que permiten justificar la cinemática con el Tensor de Esfuerzos determinado a partir de mediciones in situ, en los años 19891991. Las diferencias del relieve de Cuba Occidental y Cuba Oriental han sido reconocidas desde mucho tiempo atrás; también hay diferencias en la propia Cuba Oriental y con relación a La Española (compuesta por 2 países, Haití y República Dominicana) (COTILLA \& CÓRDOBA, 2010) (Fig. 5B). Esos autores estudiaron en detalle las fracturas de 12 áreas en Cuba Oriental, entre ellas están 4 localidades: 1) Baracoa; 2) Guantánamo; 3) Maisí; y 4) San Antonio del Sur. Así se tienen algunos valores de: A) la densidad de fracturas (fracturas $/ \mathrm{m}^{3}$ ) en: $\mathrm{Cabo} \mathrm{Cruz}=4,6$, Punta de Maisí= 4,4, Gibara = 3,9, Baracoa $=3,7$ y San Antonio del Sur= 2,7; B) la longitud de fracturas $(\mathrm{km})$ por cuenca en: Santiago de $\mathrm{Cuba}=1.350$, Toa $=862$, Guantánamo $=$ 765, Gibara $=394$ y San Antonio del Sur= 155; y C) la dimensión fractal que resulta ser diferente en: Santiago de Cuba= 1,98, Guantánamo=1,47 y San Antonio del Sur= 0,92 . De esta información destaca que San Antonio del Sur no es, desde el punto de vista neotectónico, significativo ni relevante en Cuba Oriental. 

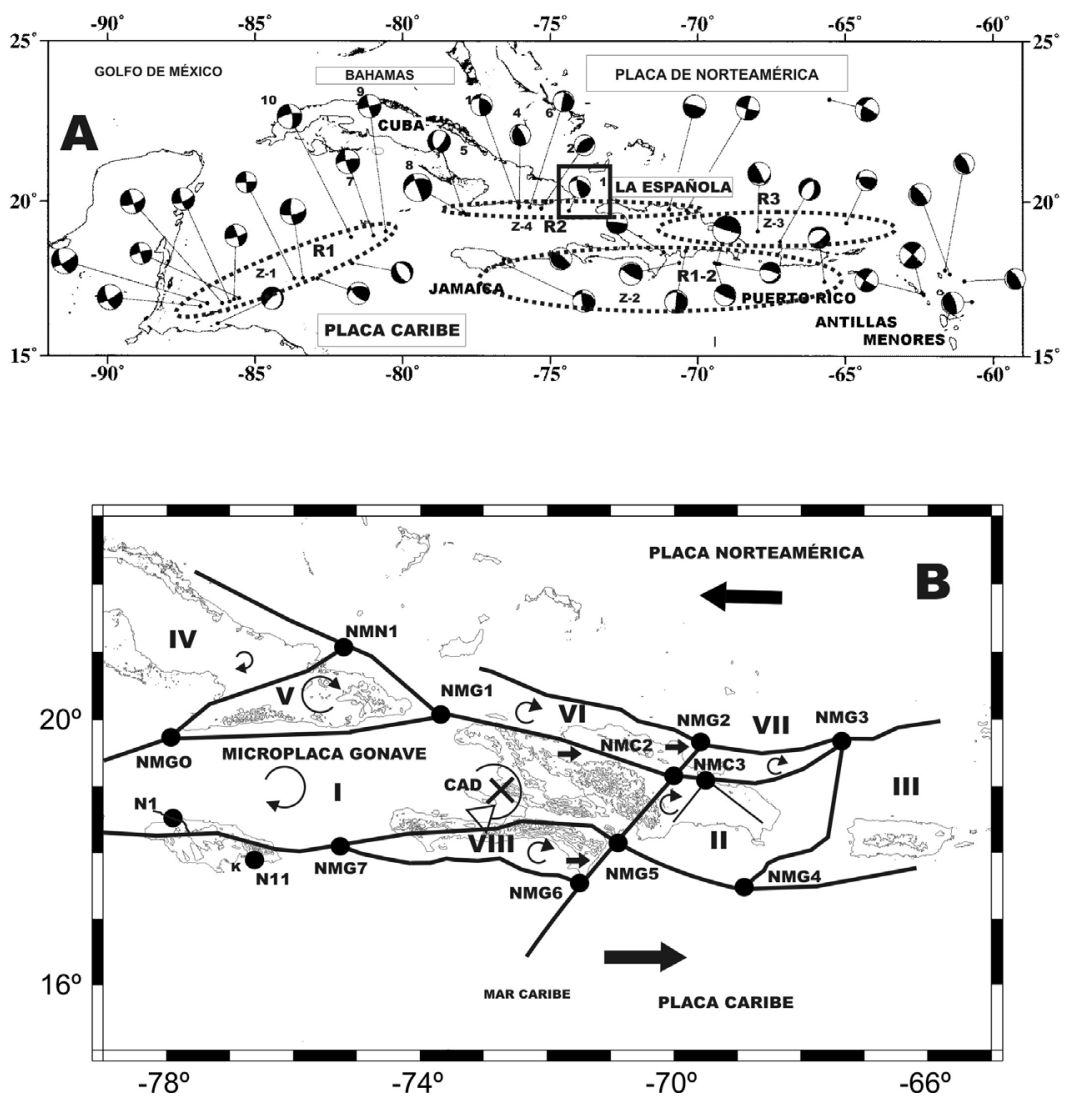

Fig. 5. Geodinámica de la parte septentrional del Caribe.

Fig. 5. Geodynamics of the northern Caribbean.

A) Selección de mecanismos focales (ver Tabla 1).

Aparecen: 1) mecanismos focales (pelotas de playa); 2) Z-1 (zona tipo 1 de mecanismos, en elipses de puntos); 3) mecanismo focal en Guantánamo (marco cuadrado); 4) Tensor Desviador R por zonas (R-1, R-2, R1-2 y R3).

B) Modelo de celdas.

Aparecen: 1) círculo negro= nudo; 2) NMG1 = acrónimo del nudo; 3) línea negra $=$ falla - alineamiento; 4) flecha arqueada $=$ sentido de movimiento de la celda; 5) línea gruesa negra $=$ sentido de movimiento de las placas y microplacas; 6) $\mathrm{II}=$ celda; 7) $\mathrm{CAD}=$ eje central de las deformaciones neotectónicas.

La zona de San Antonio del Sur (Fig. 1B) ha sido considerada, por algunos especialistas cubanos y extranjeros, como "clave" de la neotectónica de Cuba Oriental; también se ha asegurado que hay sismo-dislocaciones. Hemos determinado que: 1) esos resultados (observaciones y conclusiones) difieren; y 2) con lo expuesto en el párrafo precedente, podemos descartarle como estructura muy importante; a esto nos referiremos más adelante. 


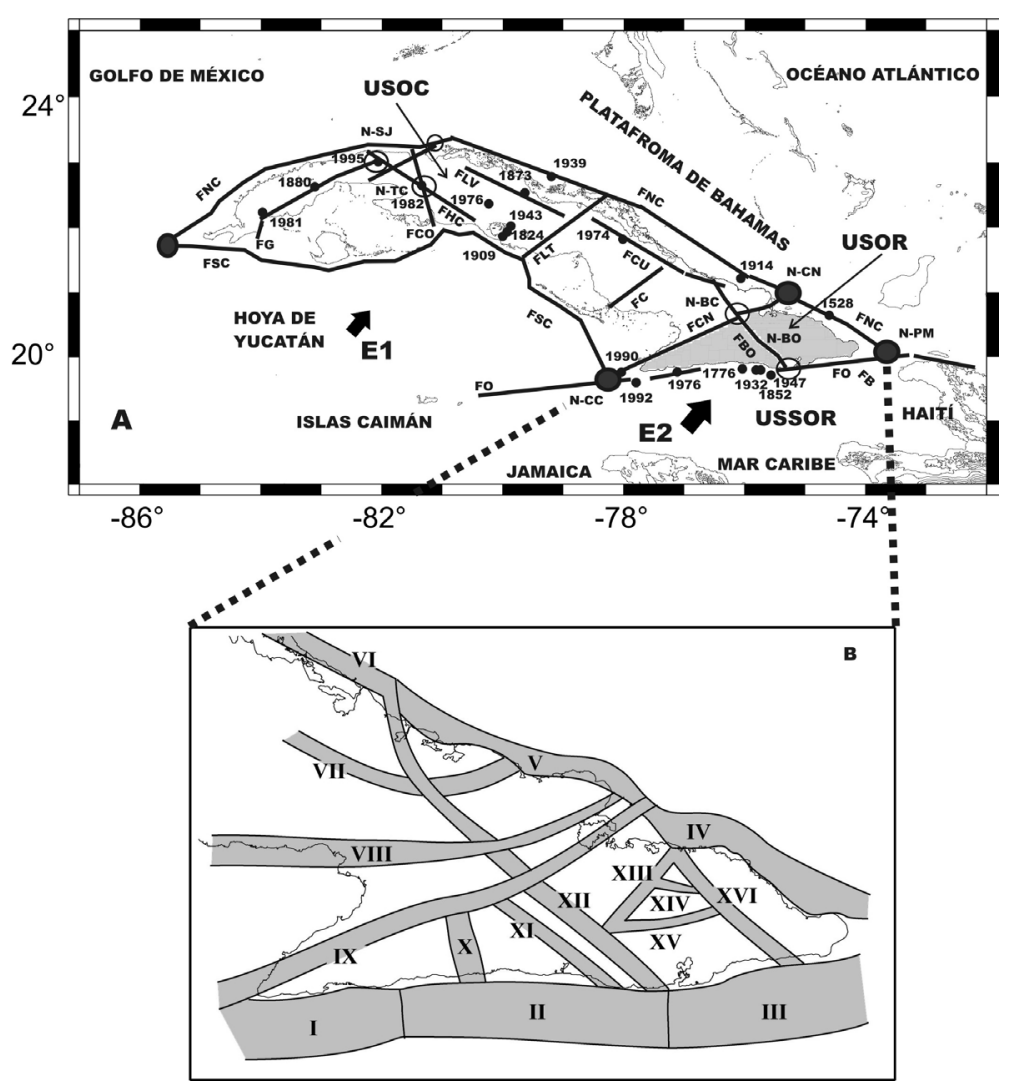

Fig. 6. Sismotectónica de Cuba.

Fig. 6. Seismotectonic of Cuba.

A) Mapa sismotectónico de Cuba.

Aparecen: unidades sismotectónicas (USOC $=$ Occidental, USC $=$ Central, $\mathrm{USOR}=$ Oriental, $\mathrm{USSOR}=$ Suroriental); siglas: $\mathrm{LP}=$ límite de placas, $\mathrm{SIP}=$ sismicidad de interior de placa; círculos negros $=$ epicentros de terremotos; $1914=$ año de ocurrencia; líneas negras $=$ fallas activas $(\mathrm{FB}=$ Baconao, $\mathrm{FC}=$ Camagüey, $\mathrm{FCN}=$ Cauto-Nipe, $\mathrm{FCO}=$ Cochinos, $\mathrm{FCU}=$ Cubitas, $\mathrm{FG}=$ Guane, $\mathrm{FH}=$ Hicacos, $\mathrm{FHC}=$ HabanaCienfuegos, FLV $=$ Las Villas, $\mathrm{FNC1}=$ Nortecubana $1, \mathrm{FNC} 2=$ Nortecubana 2 , $\mathrm{FNC3}=$ Nortecubana $3, \mathrm{FO}=$ Oriente, $\mathrm{FSC}=$ Surcubana, FLT $=\mathrm{La}$ Trocha); círculos $=$ zonas de interacción de las fallas (N5, N7, ND, NE y NF).
B) Mapa de zonas sismogeneradoras de Cuba Oriental (COMISIÓN AD HOC, 1991).

Aparecen: bandas irregulares de color gris (identificadas con I-XVI).

A lo largo de la costa $\mathrm{S}$ de Cuba Oriental hay varias cuencas cuaternarias (Cajobabo, Imías y San Antonio del Sur) y 2 bahías (Guantánamo y Santiago de Cuba) (Fig. 2A). Todos esos elementos tienen la influencia de los esfuerzos tectónicos contemporáneos. La forma geométrica de las bahías muestran diferencias en cuanto a la litología, la morfología y la cantidad y dirección de las fracturas. En Santiago de Cuba prevalece la dirección NE-NNE y en Guantánamo la N-S y E-O. 
Los valores de fracturas en las bahías de Santiago de Cuba y Guantánamo son 2,865 y 1,372 , respectivamente. Otras 2 áreas de importancia del tramo costero mencionado son Pilón y Baconao (Fig. 1B). Éstas son estructuras tectónicas deprimidas que tienen un eje principal E-O y están asociadas con fuertes terremotos (Fig. 6A). Ellas se contraponen, en el macrobloque montañoso Sierra Maestra, como morfoestructuras de distinto tipo (transtensivo y transpresivo, respectivamente) $\mathrm{y}$ orden (IV y V, respectivamente); y se localizan en los extremos septentrionales de la zona más profunda de la fosa Oriente. Indicamos que desde Baconao hasta Punta de Quemado (donde está la Bahía de Guantánamo) (Fig. 1B) el relieve costero es totalmente distinto al tramo anterior, Cabo Cruz-Baconao (donde se localiza la Bahía de Santiago de Cuba).

Datos y características de las costas y los sistemas de terrazas costeras aparecen principalmente en: ARTEAGA BARRIOS (1989); BUSTO (1975); GONZÁLEZ et al. (2003); ITURRALDE VINENT (2013); KARTASHOV et al. (1981); IONIN et al. (1977); RAMÍREZ \& SOSA (1989); y SHANTZER et al. (1976). ITURRALDE (2013) plantea 4 tramos de costa diferentes en Cuba Oriental: 1) Gibara-Boca del Yumurí (Punta Silencio); 2) Punta SilencioSantiago de Cuba; 3) Santiago de CubaPilón; y 4) Pilón-Cabo Cruz. ARTEAGA BARRIOS (1989) y RAMÍREZ \& SOSA (1989) hacen una mayor diferenciación, que COTILLA et al. (1991D) comprobaron. Lo fundamental de esos resultados es la diferencia lateral del relieve costero.

Con relación a algunos de esos tramos costeros [TC/] de Cuba Oriental indicamos las siguientes características en cuanto a la dirección principal: A) 1) $\mathrm{TC} /$ Punta Mal Año (E de la Bahía de Guantánamo)Baitiquirí SO-NE; y 2) TC/ San Antonio del Sur-Punta Caleta O-E (se corresponde con las cuencas de Baitiquirí e Imías que plantean CALAIS \& MERCIER DE
LÉPINAY (1991)). Esta última dirección se encuentra también: 1) en el PPPO (San Luis-Maisí); y 2) al N de Haití (COTILLA \& CÓRDOBA, 2010A, 2009, 2003); B) TC/ Punta Mal Año (E de la Bahía de Guantánamo)-Playa Uvero-Playa YateritasTortiguilla $(\sim 15 \mathrm{~km})$, dirección NE. Está asociado por el $\mathrm{N}$ con varias sierras (1) del Bazin, 2) Mariana (544 m), y 3) de Caujerí $(720 \mathrm{~m}) ; \mathrm{C}) \mathrm{TC} / \mathrm{Tortiguilla-San}$ Antonio del Sur (Sabanalamar), dirección E-O, se asocia con las sierras (1) Costera (Loma de los Aposentos), y 2) del Convento (805 m). Estos 2 últimos tramos están separados por el Río Sabanalamar-Caujerí, que se flexiona a 2,5 $\mathrm{km}$ de la desembocadura al O. El desvío está relacionado con una depresión transversal O-E (Los Siguatos, Oquendo, San Antonio del Sur, Cardona y Macambo) de $15 \mathrm{~km}$ de extensión, mientras que al $\mathrm{N}$ del tramo costero de Imías hay otra depresión transversal de $10 \mathrm{~km}$ (que cruza las localidades de Domingo Pérez, El Canal, El Salado y Guajacal) que relacionamos con la inflexión del Río Imías para conformar un arco cóncavo al E. Entre esas 2 depresiones hay un levantamiento que afecta al tramo final del Río Mayabí-Yacabo Abajo. En este segmento (Yacabo Abajo-Imías) existe una morfoestructura costera E-O $\left(\mathrm{h}_{\text {máx }}=389\right.$ m) muy bien definida, que se ajusta a la dirección de la falla Oriente y que hemos indicado anteriormente.

Identificar y clasificar las formas del relieve de las costas es útil para fundamentar la tectónica activa. En este sentido vemos que $\mathrm{CO}$ tiene 2 tipos de costa de choque: 1) colisión de placas; y 2) arcos de islas. En la figura $2 \mathrm{~A}$ se muestran 2 subtipos dentro del de colisión de placas $(1=$ Baitiquirí; y $2=$ San Antonio del Sur). Esos lugares están localizados en sucesión de $\mathrm{O}$ a $\mathrm{E}$ y tienen un conjunto de elementos típicos en el relieve del levantamiento. El $2^{\circ}$ subtipo es más complejo, ya que tiene no sólo deformaciones de las terrazas, sino que es cortado por una corriente fluvial de importancia (Río Sabanalamar). Consideramos que hay que estudiar las 
terrazas costeras y las estructuras y los elementos dinámicos transversales a ellas, como los ríos, y sus terrazas y valles. A este asunto dedicaremos posteriormente nuestra atención.

De otra parte, CALAIS \& MERCIER DE LÈPINAY (1991) determinaron que al S de Cuba Oriental (en la fosa de Oriente), entre Aserradero (en la Sierra Maestra) y Baitiquirí (E de Guantánamo), hay una gran zona de deformación submarina (ancho $\sim 15$ km y largo $\sim 80 \mathrm{~km}$ ) que denominan Cinturón Deformado de Santiago (Fig. 3A). Este elemento, con la forma de un arco cóncavo al S, entendemos explica la diferenciación de los esfuerzos, la actividad sísmica y los mecanismos de foco en el segmento de Cabo Cruz-Punta de Quemado, ya que tiene reflejo en el relieve del segmento costero de Bahía de Santiago de Cuba a Baitiquirí (en Guantánamo). Los autores se han referido, en otros trabajos, a las formas cóncavas de las estructuras del Caribe y de Cuba, y así indicamos, como muy relevante, la determinada en las inmediaciones de $\mathrm{La}$ Habana-Matanzas (parte noroccidental) (Fig. 3A), donde el arco es cóncavo al $\mathrm{N} \mathrm{y}$ donde se localiza el espectacular cambio de las direcciones de Cuba de NE a SE. Todo esto, evidentemente, es el resultado de los esfuerzos tectónicos y de la competencia entre estructuras. A ello también nos referiremos posteriormente.

El S de Guantánamo tiene características geodinámicas de mucho interés. Así comprobamos que Guantánamo: 1) está más alejado del centro de generación de corteza oceánica que Santiago de Cuba (Fig. 4A); 2) no tiene asociación directa con la fosa de oriente como Santiago de Cuba; 3) está entre 2 áreas con terremotos fuertes (Cabo Cruz-Baconao y $\mathrm{N}$ de Haití) que ella no ha tenido (figs. 4B y 6A); 4) posee una morfología litoral muy diferente a la que tiene el segmento Cabo Cruz-Bacnao; y 5) posee un sistema de terrazas marinas similar al del $\mathrm{N}$ de Haití (Molé), pero muy poco deformado (COTILLA \& CÓRDOBA,
2009). En este sentido, para Guantánamo las áreas de deformación de las terrazas (inflexiones y discontinuidades) son ocupadas por corrientes fluviales de valles encajados (por ejemplo: el Río Yumurí y el Río Sabanalamar).

\section{SISMICIDAD, SÍSMICA Y GRAVIMETRÍA}

Sobre la base de la experiencia se han seleccionado los siguientes resultados para: 1) la sismicidad: ÁLVAREZ \& CHUY (1992); ÁLVAREZ et al. (2001, 1999, 1990, 1985, 1984); CHUY (1980); COTILLA (2014B, 2012, 2007, 2003, 1999, 1998B, C, D, 1993); COTILLA \& CÓRDOBA (2010B, C, 2008); COTILLA \& UDÍAS (1999B); COTILLA et al. (2007, 1997A, B); MIRZOEV et al. (1989); MORENO TOIRÁN (2002); POEY (1857, 1855A, B); PRENTICE et al. (2010); RUBIO et al. (1984); SYKES \& EWING (1965); TABER (1922); VAN DUSEN \& DOSER (2000); y ZAPATABALANQUÉ(2008); y 2) el campo de la sísmica y gravimetría: BOVENKO et al. (1980); BRESZNYÁNSZKY et al. (1983); BUSH \& SHERBAKOVA (1986); CUEVAS (1998); MORENO et al. (2002); OLIVA GUTIÉRREZ (1986); PROL et al. (1993); ROSENCRATZ \& MANN (1991); SHEIN et al. (1985A); SHERBAKOVA et al. (1977); y SOLOVIEV et al. (1989). El aporte fundamental de estos trabajos es que podemos asegurar que Cuba tiene 2 tipos de sismicidad: 1) al interior de placas (Cuba Occidental, Cuba Central y Cuba Oriental); y 2) entre placas (S de Cuba Oriental). Nuestra atención se dirige a Cuba Oriental y al $\mathrm{S}$ de Cuba Oriental, ya que Guantánamo está en el primer tipo de sismicidad, pero tiene la influencia del $2^{\circ}$ tipo.

La sismicidad de Cuba y su entorno inmediato, en 2 periodos diferentes, se representa en las figuras $8 \mathrm{~A}$ y B. Destacan en ellas las agrupaciones de epicentros en el S de Cuba Oriental, donde está la falla Oriente ( $\mathrm{N}^{\mathrm{os}} 1,2,3$ y 4, en la figura 
4A), mientras que en las tablas 1 y 2 se presentan: 1) una selección de mecanismos focales para el segmento septentrional del Caribe (Fig. 5A) y 2) los terremotos más significativos de la parte suroriental de Cuba (figs. 4B y 6A), respectivamente. También en las figuras $6 \mathrm{~A}$ y $7 \mathrm{~A}$ indicamos algunos terremotos importantes de las partes Occidental y Central. En este sentido, Cuba ha incrementado por periodos la cantidad de estaciones sísmicas permanentes en Cuba Oriental. Esas estaciones son Cascorro, Las Mercedes, Maisí, Moa y Río Carpintero (Fig. 4B). En la actualidad, la detección de la red de estaciones del Caribe (JamaicaPuerto Rico) contribuye, decisivamente, a la determinación de la sismicidad de esa región cubana (Tabla 3 ).

Sostenemos que: 1) el $1^{\text {er }}$ terremoto reportado en Cuba fue en Baracoa en 1528 ; 2) el terremoto del 19.03.1854 se asocia también a Baracoa; 3) los datos de los fuertes terremotos de 1766 y 1932 en Santiago de Cuba (Fig. 6A) muestran que 2 localidades de Guantánamo tuvieron valores de $I_{\text {máx }}$ (escala MSK): 3.a) 6 (Baitiquirí) y 3.b) 5 (Baracoa) (COTILLA 2003); 4) en Guantánamo nunca se ha reportado tsunami alguno; y 5) los rangos de profundidad focal para Guantánamo son similares a los determinados en Cabo Cruz-Baconao. También, a partir de datos de la red de estaciones sísmicas, se puede asegurar que la actividad sísmica en Guantánamo está: 1) en el extremo oriental (al E de Punta de Quemado), hacia el Paso de los Vientos; 2) al N, entre Bahía de Nipe y Punta de Quemado (sobre la falla Nortecubana); 3) al SE de la Bahía de Guantánamo (en la falla Oriente); 4) en la zona interior del Grupo Nipe-Sagua-Cristal-Baracoa-Purial (principalmente sobre la falla Purial) (figs. 7B, 8C y D); y 5) en la zona de Moa-Baracoa (en la falla Nortecubana) donde se han registrado, recientemente, varios terremotos de importancia: 5.a) 20.03.1992, $\mathrm{Md}=4,23$; 5.b) 28.12.1998, $\mathrm{Mb}=5,4 ; 5 . c)$ 05.01.1999, $\mathrm{Mb}=4,7$; y 5.d) 05.01.1999, $\mathrm{Mb}=4,5$. Así se puede considerar que la zona $\mathrm{N}$ de Guantánamo tiene mayor actividad sísmica que la zona $\mathrm{S}$.

Tabla 1. Selección de mecanismos focales (Cabo Cruz-Punta de Quemado).

Table 1. Selection of focal mechanisms (Cabo Cruz-Punta de Quemado).

\begin{tabular}{|c|c|c|c|c|c|}
\hline $\mathbf{N}^{\mathbf{0}}$ & Fecha & Ms & $\mathbf{N}^{\mathbf{0}}$ & Fecha & Ms \\
\hline 1 & 13.11 .1978 & 5,1 & 6 & 04.09 .1990 & 5,2 \\
2 & 01.09 .1985 & 5,1 & 7 & 26.08 .1991 & 5,2 \\
3 & 12.02 .1989 & 5,2 & 8 & 25.05 .1992 & 6,9 \\
4 & 22.05 .1990 & 5,1 & 9 & 27.06 .1992 & 5,3 \\
5 & 26.08 .1990 & 5,9 & 10 & 27.06 .1995 & 5,6 \\
\hline
\end{tabular}

En la figura 7 de MORENO TOIRÁN (2002) se distinguen 6 agrupaciones de epicentros que COTILLA (1993) indicó y analizó desde tiempo antes. Ellas son: 1) NE de la Bahía de Nipe; 2) S y SE de la Bahía de Guantánamo; 3) Punta de Quemado-Haití; 4) Cabo Cruz; 5) S del Pico Turquino-Baconao (la mayor); y 6) interior de Cuba Oriental. También MORENO TOIRÁN (2002), en su doble figura 6 (periodo 1979-1989) y su figura 1 (periodo 1998-2000), confirma esas agrupaciones. Aquí presentamos las figuras $4 \mathrm{~B}, 8 \mathrm{C}$ y D, donde se aprecian los agrupamientos de los epicentros instrumentales. 
Tabla 2. Terremotos más significativos de la parte suroriental de Cuba.

Table 2. More significant earthQuakes of the southeastern Cuba.

\begin{tabular}{|c|c|c|c|c|}
\hline Fecha & $\begin{array}{c}\text { Coordenadas } \\
\text { (lat N / lon O) }\end{array}$ & Profundidad (km) & $\begin{array}{c}\text { Intensidad Máxima } \\
\text { (MSK) }\end{array}$ & Localidad \\
\hline 1766.06 .12 & $19,9 / 76,1$ & 30 & 9 & Santiago de Cuba \\
1852.08 .20 & $19,9 / 75,9$ & 30 & 9 & Santiago de Cuba \\
1932.02 .03 & $19,8 / 75,8$ & 50 & 8 & Santiago de Cuba \\
1947.08 .07 & $19,9 / 75,3$ & 50 & 8 & Santiago de Cuba \\
1976.02 .19 & $19,87 / 76,87$ & 15 & 6 & Pilón \\
1990.08 .26 & $19,59 / 77,87$ & 10 & 8 & Cabo Cruz Cruz \\
1992.05 .25 & $19,61 / 77,87$ & 23 & & \\
\hline
\end{tabular}
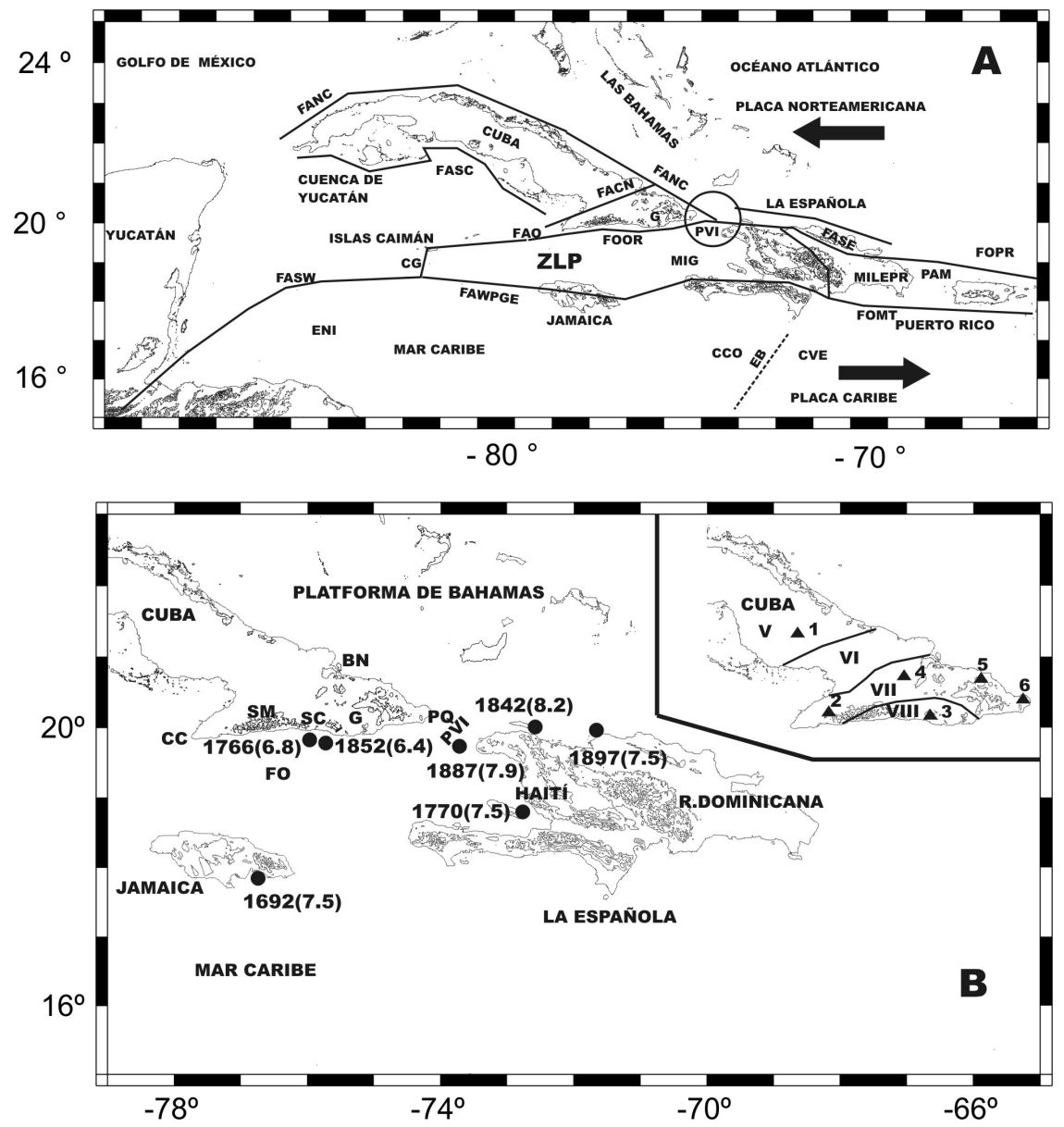

Fig. 7. Tectónica activa del Caribe.

Fig. 7. Active tectonic of the Caribbean. 
La precisión de las determinaciones de epicentros en Cuba Oriental ha sido siempre mayor que en el resto de Cuba. Sin embargo, se ha prestado más atención a la actividad sísmica del entorno inmediato al S de Santiago de Cuba, que al territorio de Cuba Oriental. Este hecho es paradójico, ya que en las figuras $7 \mathrm{~B}, 8 \mathrm{C}$ y D resalta la importante actividad sísmica de Cuba Oriental. Todos esos terremotos están en el área interior de la detección de la red cubana, donde la precisión es la mejor. Evidentemente hay una, muy importante, limitación teórico-práctica para el conocimiento de la sismicidad y la peligrosidad sísmica de Cuba Oriental, por el no estudio de los terremotos débiles de la Unidad Sismotectónica Oriental (Fig. 6B). Esta situación se expuso por Cotilla desde el año 1993 y lamentablemente en 2015 persiste.

A) Esquema de la tectónica del Caribe Septentrional

Aparecen: 1) las placas del Caribe y de Norteamérica; 2) los sentidos de movimiento de las placas (flechas gruesas negras); 3) la zona límite de placas (ZLP); 4) las fallas principales (FASW $=$ Swan-Walton, $\quad \mathrm{FAO}=$ Oriente, FACN $=$ Cauto-Nipe, FANC= Nortecubana, $\quad \mathrm{FASC}=$ Surcubana,
FASE $=$ Septentrional, FAWPGE $=$ Walton-Planatin Garden-Enriquillo); 5) las fosas oceánicas $(\mathrm{FOOR}=$ Oriente, $\mathrm{FOMT}=$ Muertos, $\mathrm{FOPR}=$ Puerto Rico); 6) el centro de generación de corteza (CG); 7) Cuencas de Yucatán, $\mathrm{CCO}=$ Colombia, $\mathrm{CVE}=$ Venezuela; 8) Pasos $(\mathrm{PV}=$ de los Vientos, $\mathrm{PAM}=$ Muertos); 9) Elevados $(\mathrm{EB}=$ Beata, $\mathrm{ENI}=$ Nicaragua); 10) Microplacas ( $\mathrm{MIG}=$ Gonave, MILEPR= La Española-Puerto Rico).

B) Selección de terremotos fuertes de un segmento del Caribe Norte.

Aparecen: 1) epicentros de terremotos (puntos negros); 2) $1852(6,4)=$ año (magnitud); 3) lugares geográficos (BN= Bahía de Nipe, $\mathrm{CC}=$ Cabo Cruz, $\mathrm{FO}=$ Fosa de Oriente, $\mathrm{G}=$ Guantánamo, $\mathrm{PQ}=$ Punta de Quemado, PVI= Paso de los Vientos, R. Dominicana= República Dominicana, $\mathrm{SC}=$ Santiago de Cuba, $\mathrm{SM}=$ Sierra Maestra); 4) recuadro (mapa de regionalización de intensidades sísmicas $(\mathrm{I}=\mathrm{V}$, escala $\mathrm{MSK}$ ) para $\mathrm{T}=$ 100 años) con las estaciones sísmicas permanentes (triángulos negros con cifras: $1=$ Cascorro, $2=$ Las Mercedes, 3= Río Carpintero, 4= Pinares de Mayarí, 5= Moa, 6= Maisí). 

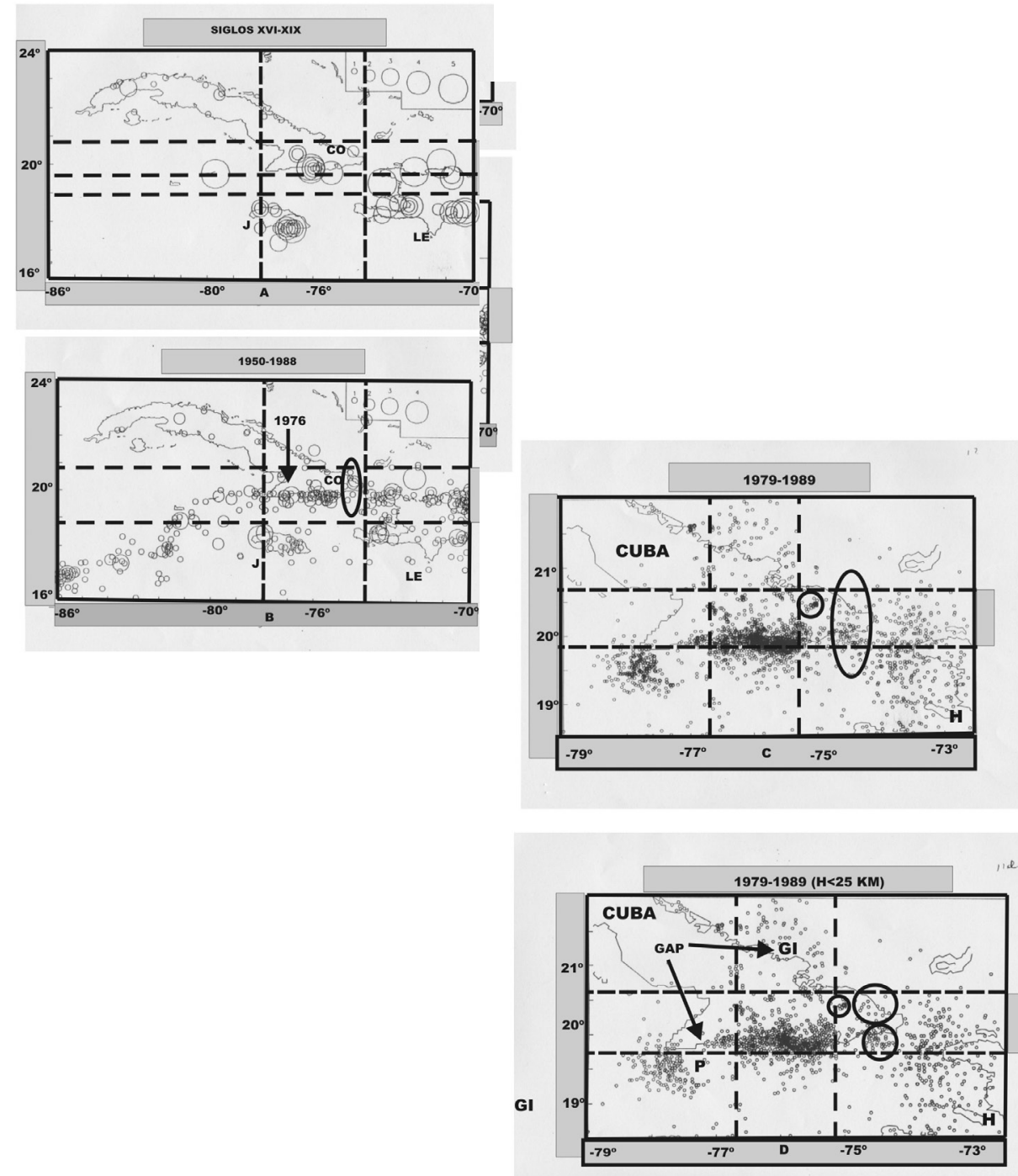

Fig. 8. Mapas de epicentros de Cuba.

Fig. 8. Epicentres' maps of Cuba.

A) Cuba: Epicentros de los siglos XVI-XIX.

B) Cuba: Epicentros del periodo 1950-1988.

Aparecen: 1) epicentros (círculos); 2) localidad $=\mathrm{CO}$ (Cuba Oriental); 3) zona de agrupamiento de epicentros (elipse).

C) Cuba Oriental: Todos los rangos de profundidad (1979-1989).
D) Cuba Oriental: Profundidad $<25 \mathrm{~km}$ (1979-1989).

Aparecen: 1) epicentros (círculos pequeños) determinados con 5 o más estaciones de Cuba Oriental; 2) zonas de agrupamiento de epicentros (círculos y elipses). 
Tabla 3. Datos de los terremotos recientes en Guantánamo (2010-2015, USGS).

Table 3. Data of ReCent earthQuakes in Guantánamo (2010-2015, USGS).

\begin{tabular}{|l|c|}
\hline Cantidad & 25 \\
\hline & $5,6-5,0=5$ \\
Rango de magnitudes & $5,0-4,0=15$ \\
& $4,0-3,0=4$ \\
& $<3,0=1$ \\
\hline & $31-20=6$ \\
Rango de profundidades $(\mathbf{k m})$ & $20-10=15$ \\
& $<10=4$ \\
\hline
\end{tabular}

La figura 8B tiene una elipse N-S para incluir un conjunto de eventos sísmicos de la provincia Guantánamo. También en las figuras $8 \mathrm{C}$ y $\mathrm{D}$ tenemos 2 y 3 envolventes de epicentros, respectivamente. Ellos se asocian a terremotos de Cuba Oriental con mayor énfasis en Guantánamo. Indicamos que esas agrupaciones se repiten en las mismas zonas y en todas las figuras. A su vez, la figura $4 \mathrm{~B}$ muestra un total de 12 agrupamientos de terremotos $(1=$ Cabo Cruz; 2= Uvero; $3=$ Sierra Maestra-Baconao; $4=$ Imías-Punta Caleta; 5= Cuchillas de Toa; 6= Cuchillas de Moa-Sagua de Tanámo; $7=$ Bahía de Nipe; $8=$ Nuevitas; $9=$ Tunas; $10=$ San Germán; $11=$ Jamaica; y $12=\mathrm{N}$ de Haití). De nuestro interés son los Nos. 4 (Punta Caleta), 5 (Cuchillas de Toa) y 12 (Haití). También hay 2 gaps sísmicos en la parte Oriental de Cuba: 1) Temporal en Gibara de 101 años; y 2) Espacial en Pilón de 39 años (Fig. 8D). Insistimos que para explicar la sismicidad de Cuba Oriental es imprescindible poseer datos de las estaciones sísmicas permanentes de Jamaica y La Española. No obstante, hemos analizado la base de datos de los terremotos con $\mathrm{M} \geq 3$ en el segmento Bahía de Guantánamo-N de Haití, del periodo 1950-2010. Esto ha permitido determinar la ocurrencia de: 1) 17 terremotos entre Bahía de Guantánamo y Punta de Quemado; 2) 25 terremotos entre Punta de Quemado y el $\mathrm{N}$ de Haití (Paso de los Vientos); y 3) 132 terremotos en el $\mathrm{N}$ de Haití. Así, tenemos una primera interpretación de la sismicidad, que permite asegurar que entre la Bahía de Guantánamo y el Paso de los Vientos: 1) hay un mínimo de AS; y 2) es el segmento menos activo de la falla Oriente.

\section{CARACTERÍSTICAS MORFOESTRUCTURALES Y MORFOTECTÓNICAS}

Los principales resultados de tipo: 1) morfoestructural se localizan en: GONZÁLEZ et al. (2003, 1989A); COTILLA et al. (2003); y HERNÁNDEZ et al. (1990, 1989, 1986); y 2) morfotectónico están en: CALAIS \& MERCIER DE LEPINAY (1993, 1991, 1990); COTILLA (2014A, 2011, 1998B, 1993); COTILLA \& UDÍAS (1999A); COTILLA et al. (1998, 1997B, 1996B, 1991C, 1988); y RODRÍGUEZ INFANTE et al. (2000, 1996). Con esa base es posible configurar un modelo inicial. Así, de acuerdo con el mapa geológico de las ACADEMIAS DE CIENCIAS DE CUBA \& HUNGRÍA (1981), las corrientes fluviales en CO están determinadas por fallas, aunque un gran número de cañadas primarias se origina sin ninguna relación con la tectónica. Sin embargo, se ha determinado que la dirección E-O que hay entre las cabezadas del Río Mayarí hasta el Río Toa está relacionada con la etapa neotectónica. También se propone que existe una relación de continuidad estructural 
entre el Río Mayarí (que corre en dirección S-N entre las sierras de Nipe y Cristal) y el tramo de igual dirección del Parteaguas Principal de Primer Orden, aunque este último está un tanto desplazado al $\mathrm{O}$ por la influencia de posibles esfuerzos NO y E-O.

A partir de la información del relieve y de la red fluvial de Cuba Oriental, incluidos en el SIG, se confecciona un Mapa de Regionalización del drenaje superficial (Fig. 1A). Éste tiene 5 áreas principales: 1) Zona Sur $(\mathrm{N}-\mathrm{S})=2$ (asociado a la fosa de Oriente); 2) Zona Norte (N-S)= 2 (asociado al hundimiento del área Nortecubana); 3) Zona Norte $(\mathrm{NE})=2$ (asociado a rotaciones de bloques); 4) Zona Sur (SE)= 1 (asociado a rotaciones de bloques); y 5) Zona Oeste $(\mathrm{NO})=2$ (asociado a rotaciones de bloques). Esta figura permite comprender que el drenaje de Cuba Oriental: 1) depende de la tectónica regional; 2) tiene manifiesta dirección $\mathrm{N}-\mathrm{S}$ en el $\mathrm{S}$; y 3) este último es muy corto; 4) la mayor densidad y heterogeneidad está en el $\mathrm{N}$ de Guantánamo. Hemos identificado una ZD-SP (N-S) entre San Antonio del Sur y Punta Caleta (pendiente de $80 \mathrm{~m}$ por $\mathrm{km}$ ), que es similar, aunque menos activa, a la del $\mathrm{S}$ de la Sierra Maestra entre Marea de Portillo y Caletón Blanco (pendiente de $150 \mathrm{~m}$ por km) [ZDSM (N-S)] (Fig. 9A).

El Parteaguas Principal de Primer Orden tiene en Cuba Oriental varias peculiaridades de mucho interés (Fig. 1C). Él se dibuja cerca y paralelo a la costa $\mathrm{N}$, bordea la cuenca del Río Cauto (el único de $7^{\mathrm{mo}}$ orden) (Fig. 1B) hasta las cabezadas del Río Gibara (SO de la Bahía de Nipe), donde toma dirección NE, alcanzando la Bahía de Santiago de Cuba, para continuar con rumbo E hasta el extremo oriental de la Isla, al S de la Punta de Maisí. También forma parte del Parteaguas Principal el tramo aproximadamente rectilíneo desde la intersección anterior, es decir, al NE de San Luis, siguiendo al S (Yerba de Güinea) y después con rumbo $\mathrm{O}$, y que corta toda la Sierra Maestra hasta las inmediaciones de Cabo Cruz. Este Parteaguas
Principal en la Sierra Maestra no se localiza sobre los máximos niveles hipsométricos del macrobloque montañoso. Este dato es muy significativo desde el punto de vista estructural y neotectónico. Pero, el aspecto fluvial más interesante lo constituye la combinación espacial y morfológica de la gran cuenca del Río Cauto y el rodeo del Parteaguas, antes señalado. Esto, asumimos, es debido al control estructural y a la actividad neotectónica. La densidad de ríos en la cuenca del Río Cauto no es la mayor, aunque sí posee la mayor área en el país. La mayor densidad está en la región Bahía de Santiago de Cuba-Pinares de Mayarí-Moa-Bahía de Guantánamo. También al E del Turquino (en la Sierra Maestra) se aprecia una importante densidad fluvial, aunque la área sea mucho menor que anterior y todos los ríos sean de orden bajo.

La región de la Sierra Maestra $(\sim 15.000$ $\mathrm{km}^{2}$ ) se caracteriza también por el fuerte gradiente del relieve de la vertiente $\mathrm{S}$ en comparación con el que posee la vertiente $\mathrm{N}$ hasta el Río Cauto (Fig. 6A), lo que motiva que los ríos alcancen un alto orden en tramos muy cortos, en contraposición a las áreas tan pequeñas de sus correspondientes cuencas. Además, las direcciones E-O del Parteaguas Principal de Primer Orden y N-S de las corrientes fluviales de esta vertiente $\mathrm{S}$ son muy significativas y se considera que dependen del control tectónico regional. Las vertientes N y S de la Sierra Maestra tienen apreciables diferencias no sólo en el gradiente del relieve y la extensión de los ríos, sino también en el diseño de sus cuencas. En tanto, en la parte $\mathrm{S}$ las cuencas son muy estrechas, prácticamente perpendiculares a la línea de costa y al Parteaguas y muy pequeñas, las correspondientes a la parte $\mathrm{N}$ son más heterogéneas con dirección $\mathrm{NO}$ y E-O (como una transición a la dirección del Río Cauto). Es factible añadir que el sistema de terrazas fluviales en la vertiente $\mathrm{S}$ es totalmente erosivo y tectónico, mientras que en la vertiente $\mathrm{N}$ hay una manifiesta combinación de tipos pero con 
menor intensidad. Reiteramos que esto es debido, principalmente, a la influencia de la neotectónica. Las irregularidades del Parteaguas Principal de Primer Orden en Cuba Oriental se observan también en La Española (COTILLA \& CÓRDOBA, 2009), lo que es indudablemente otro elemento de la vinculación tectónica entre ambos territorios.

Hay otras 3 características del macrobloque Sierra Maestra que justifican en él la influencia neotectónica: 1) el mayor ancho coincide con la posición entre el Pico Turquino y la Bahía de Santiago de Cuba (donde hay una diferencia de altitud de $\sim 10$ $\mathrm{km})$; 2) aquí la rama del Parteaguas Principal de Primer Orden tiene dirección E-O y está muy cercana a la costa $S$; y 3 ) hay un muy fuerte gradiente del relieve (el mayor del Caribe). Además existe un elemento que tiende a compensar el complejo cuadro morfoestructural de la región central de Cuba Oriental, que se visualiza con: 1) el sistema escalonado de llanuras y alturas de Cauto-Nipe (dirección NE) y de San Luis (con dirección NO), confundiéndose, esta última, en su extremo oriental con la depresión de Guantánamo, a través de un sistema de alturas con igual dirección; 2) la distancia entre las costas $\mathrm{N}$ y $\mathrm{S}$ disminuye de $\mathrm{O}$ a $\mathrm{E}$, al igual que sucede con la fosa de Oriente; 3) la inmediata cercanía y localización del Cinturón Deformado de Santiago; y 4) la inestabilidad de las pendientes, en particular en Guantánamo: Puriales de Caujerí, Cuchillas del Toa y de Baracoa (Fig. 2A).

El par de sistemas montañosos, Grupo NipeSagua-Toa-Baracoa-Purial / Sierra Maestra, se distingue por varias características, entre ellas: 1) ocupan el $\sim 90 \%$ del territorio de Cuba Oriental y son 2 macrobloques independientes; 2) a $\mathrm{h}_{\text {máx }}(\mathrm{m})$ es: $\sim 1.200$ / 1.974 ; 3) la amplitud máxima de los movimientos neotectónicos verticales (más jóvenes, en m) es: $\sim 50$ / 120 y más antiguos $(10 \mathrm{~m} / 55 \mathrm{~m})$; 4) tienen sistemas de bloques: irregulares y asimétricos asociados con fallas y fracturas jóvenes y antiguas / regulares y simétricos asociados con fallas y fracturas recientes; 5) el Parteaguas Principal de Primer Orden: sólo se define en la parte SO / está en todos los bloques principales; 6) la cantidad de corrientes fluviales de $3^{\circ}-6^{\circ}$ órdenes es: $240 / 165 ; 7$ ) el Índice de Simetría Estructural es: 1,23 / $0,54 ; 8)$ la dirección de la morfoestructura principal es: $\mathrm{NO} / \mathrm{E}-\mathrm{O}$; 9) el drenaje tiene dirección: diversa / principalmente N-S y $\mathrm{S}-\mathrm{N}$; 10) la cantidad de valles en "V" es: 198 / 219; y 11) contraposición con una fosa oceánica: no existe / es con la fosa de Oriente. Estos datos permiten confirmar que la Sierra Maestra es la morfoestructura montañosa más activa de Cuba Oriental.

En ambas vertientes de Cuba Oriental hay más de 25 ríos de $5^{\circ}-7^{\circ}$ órdenes. En la vertiente $\mathrm{N}$ hay ríos de: 1) $5^{\circ}$ orden $=6$ (Cananova, Duaba, Levisa, Moa, Nipe, Tana y Yumurí); y 2) $6^{\circ}$ orden $=6$ (Hondo, Mayarí, Sagua de Tanámo, Tacajó, Toa y Yara). Mientras que en la vertiente $\mathrm{S}$ son de: 1) $5^{\circ}$ orden= 11 (Cañas, Guamá, Hondo, Imías, Jajo, Javen, La Mula, San Juan, Sabanalamar, Sardinero y Sevilla); 2) $6^{\circ}$ orden $=$ 1 (Guantánamo); y 3) $7^{\circ}$ orden $=1$ (Cauto). Es decir, el río de mayor orden está en la zona del basculamiento, al SO de la cuenca Cauto-Nipe. También hemos determinado que los ríos Duaba y Toa corren, por un tramo de $\sim 20 \mathrm{~km}$, paralelos a la costa $\mathrm{N}$, de Baracoa, y separados entre sí en $10 \mathrm{~km}$. Esto lo hemos estudiado al O de Toa y Punta Guanico, exactamente en el meridiano de San Antonio del Sur. Ellos conforman un bloque transversal elevado de dirección NE (Fig. 9B).

Entre las cuencas de interés neotectónico en Guantánamo está la del Río CaujeríSabanalamar, en el N San Antonio del Sur. Esa zona que ha despertado mucho interés a algunos especialistas tiene: 1) un Índice de Asimetría de 0,$1 ; 2$ ) un Índice de Gavelius de 0,$25 ;$ y 3 ) una dirección de drenaje prácticamente perpendicular $(\mathrm{N}-\mathrm{S})$ a la costa (Fig. 9B). Características similares 
también se determinaron en otros 2 ríos de Guantánamo: Baracoa y Yumurí. Pero éstos drenan en la costa septentrional aunque en la misma longitud geográfica y tienen relación espacial con un escarpe morfoestructural que cae al E a partir del meridiano Punta Caleta (costa S) y Punta del Fraile (costa N). En ese mismo sector drena (de O a E) el Río Maya ( $3^{\text {er }}$ orden), desde Gran Tierra hacia Punta de Maisí (coeficiente de sinuosidad= 0,95 y pendiente media de $48,5 \%$ ). El valle del Río Caujerí tiene varios sectores con movimientos ascendentes, evidenciados a partir de: 1) la definida alineación N-S de $\sim 23 \mathrm{~km}$ Puriales de Cuajerí-San Antonio del Sur; 2) la asimetría transversal de su valle; 3) el sistema predominante de valles con forma "V"; y 4) la intensa erosión de los depósitos del Cuaternario. También en 6 transectos [T/]: 1) T/ Puriales de CaujeríEl Palmar, sobre el Río Caujerí-Sabalamar $(\sim 1 \mathrm{~km})$, hay varias fracturas abiertas. Ellas se asocian con fallas normales en un marco de distensión; 2) T/ El Palmar-La Criolla muestra un proceso mucho más evidente del fallamiento que afecta al curso fluvial (arco cóncavo de $\sim 2 \mathrm{~km}$ de longitud) hasta Los Asientos; 3) T/ Los Asientos-Palmarito tiene algunas fallas E-O; 4) en T/ Palmarito-Lajas de Caujerí, las fracturas están abiertas; 5) T/ Mariana-Segundo Frente (al NO de la Sierra del Convento) tiene fracturas abiertas N-S y E-O; y 6) T/ al S de Sierra de Mariana (O del río)-Sierra del Convento (E del río) existe un sistema de alineaciones SO-NE y E-O. Existe aquí una cuenca aluvial en dirección E-O que ocupa la zona de Oquendo-San Antonio del Sur (Fig. 2B).

En la figura 9A también aparecen: A) 2 zonas anómalas de inflexiones bruscas (de $\sim 90^{\circ}$ ) del drenaje superficial en Guantánamo (indicadas con cuadrados negros y números $1=$ Los Llanos $(\mathrm{S}$ de Cuchillas de Toa), y $2=\mathrm{S}$ de Cuchillas de Baracoa); B) una selección de alineaciones; C) 3 bloques con descenso significativo (Guantánamo, Nipe-Sagua y E de Baracoa); D) el escarpe S-N entre Punta Caleta y Punta del Fraile; E) 5 zonas peculiares de drenaje (Cauto, Moa-Baracoa, Nipe-Sagua, Sierra Maestra y S de la Sierra de Purial); F) 2 gaps sísmicos (Espacial en Pilón (año 1976) y Temporal en Gibara (1914)); y G) 6 zonas con importante actividad sísmica (Baracoa, Cabo Cruz, Guantánamo, Maisí, Nipe y Sierra Maestra). La figura 9B complementa la información precedente con los siguientes elementos: A) sistemas de bloques con ascensos significativos en la etapa actual (Cuchillas de Baracoa, Cuchillas de Toa, Sierra de Cristal, Sierra Maestra y Sierra de Nipe). Se indican los sistemas de bloques más importantes (rectángulo y cuadrados negros: 1) Baracoa, y 2) $\mathrm{N}$ de las Cuchillas de Toa); B) bloques en descenso intercalados, principalmente, entre los anteriores; C) alineaciones del relieve relacionadas con esas estructuras; D) selección de epicentros de terremotos del año 2015; E) el sentido del basculamiento, asimétrico, de la cuenca Cauto-Nipe; y F) la zona del máximo gradiente del relieve, en el S de la Sierra Maestra. Estos autores sostienen que en Cuba Oriental hay 4 zonas sismogénicas principales: 1) Oriente $\left(1^{\mathrm{a}}\right.$ Categoría); 2) Surcubana (2a Categoría); 3) Baconao ( $3^{\mathrm{a}}$ Categoría); 4) Purial ( $3^{\mathrm{a}}$ Categoría). Además distinguen que: 1) esas zonas están segmentadas; 2) Baconao es más activa que Purial. 

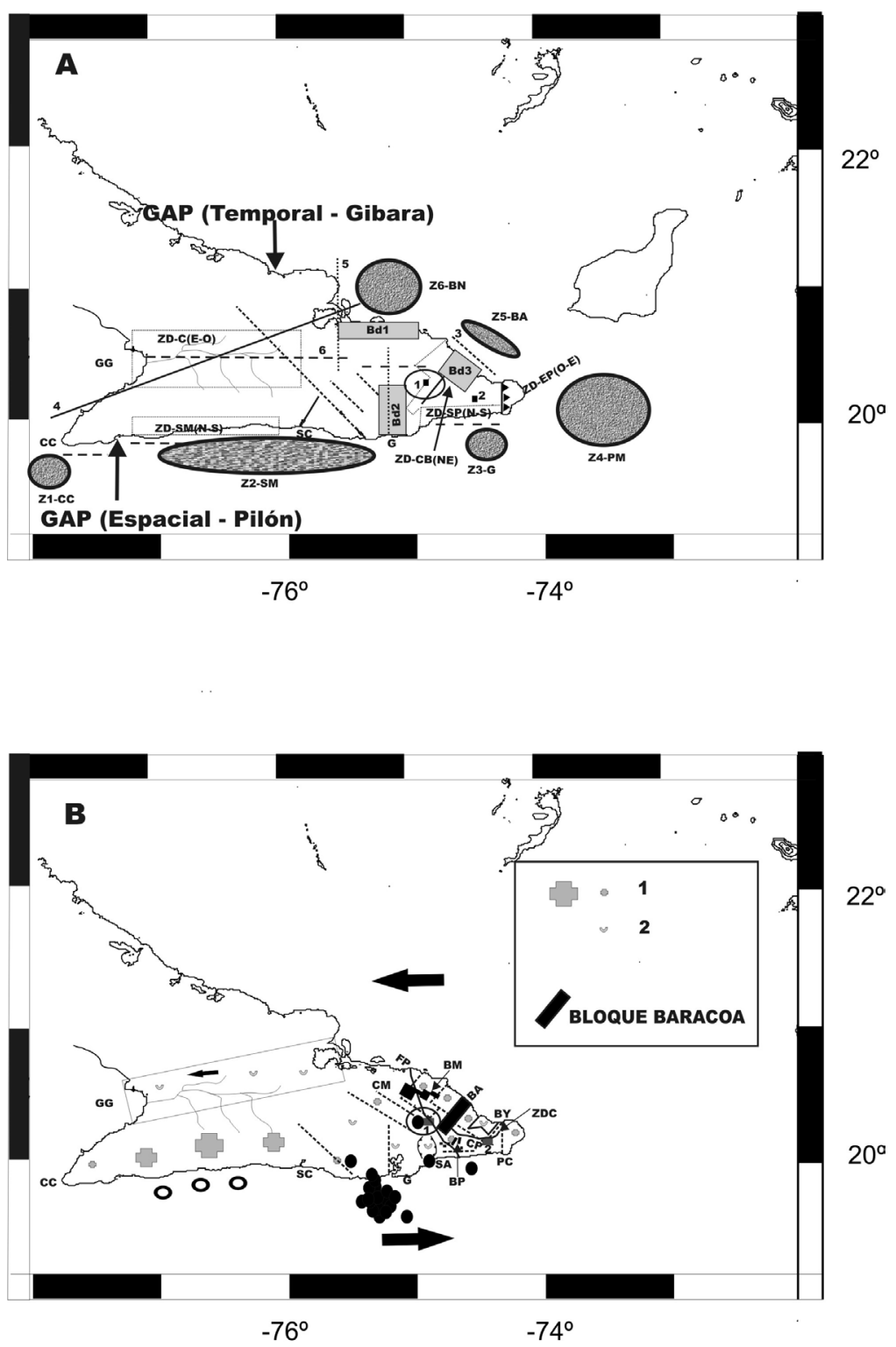

Fig. 9. Morfoestructuras de Cuba Oriental.

Fig. 9. Morphostructures of Eastern Cuba. 
A) Esquema

morfoestructural complementario (área de Guantánamo).

Aparecen: 1) zonas anómalas (recuadrados negros 1 y $2=$ desvío fluvial de $90^{\circ}$ ); 2) direcciones de las principales alineaciones $(3=\mathrm{NO} ; 4=$ $\mathrm{NE}$; $5=\mathrm{N}-\mathrm{S} ; 6=\mathrm{E}-\mathrm{O}$ ); 2) localidades $(\mathrm{CC}=$ Cabo Cruz, $\mathrm{G}=$ Guantánamo, $\mathrm{GG}=$ Golfo de Guacanayabo, $\mathrm{SC}=$ Santiago de Cuba); 3) zonas de drenaje (rectángulos de puntos, ZD-C $(E-O)=$ Cauto, $\mathrm{ZD}-\mathrm{CB}(\mathrm{NE})=$ Cuchillas de Toa, $\mathrm{ZD}-\mathrm{SM}(\mathrm{N}-\mathrm{S})=$ Sierra Maestra, $\mathrm{ZD}-\mathrm{SP}(\mathrm{N}-\mathrm{S})=$ Sierra del Purial, ZD-E Purial(O-E)); 4) bloques de descenso significativo $(\mathrm{Bd} 1=$ Nipe-Sagua, $\mathrm{Bd} 2=$ Guantánamo, $\mathrm{Bd} 3=\mathrm{E}$ de Baracoa); 5) zonas de importante actividad sísmica (círculos y elipses con relleno: $\mathrm{Z1}-\mathrm{CC}=$ Zona 1 de Cabo Cruz, Z2-SM= Zona 2 de Sierra Maestra, Z3-G= Zona 3 de Guantánamo, Z4-PM= Zona 4 de Punta de Maisí, Z5-BA= Zona 5 de Baracoa, Z6-BN=Zona 6 de Bahía de Nipe); 6) escarpe N-S del E de Purial; 7) dos GAPS sísmicos (Espacial: Pilón= 39 años; Temporal: Gibara=101 años).

B) Principales zonas activas.

Aparecen: 1) localidades $(\mathrm{BA}=$ Baracoa, $\mathrm{BY}=$ Boca de Yumurí, $\mathrm{CC}=$ Cabo Cruz, $\mathrm{G}=$ Guantánamo, $\mathrm{CM}=$ Cuchillas de $\mathrm{Moa}, \mathrm{CP}=$ Cuchillas de Purial, $\mathrm{MO}=$ Moa, $\mathrm{PC}=$ Punta Caleta, $\mathrm{SA}=$ San Antonio del Sur, $\mathrm{SC}=$ Santiago de Cuba); 2) bloques de ascenso (1), bloques de descenso (2); 3) dirección de basculamiento (flecha negra); 4) escarpe de San Antonio del Sur; 5) zona de máximo gradiente del relieve (anillos); 6) zonas anómalas (cuadrados negros 1 , $2=$ desvío fluvial de $90^{\circ}$ ); 7) selección de alineaciones; 8) epicentros del 2015 (USGS) (círculos negros).

Para Cuba Oriental, MAKAROV (1987, 1986) representa en su figura 1 las siguientes estructuras neotectónicas: 1) Sistemas de levantamientos Sierra Maestra-
Baracoa (con las unidades menores de: Sierra Maestra, Sierra de Nipe, Sierra del Cristal, Cuchillas de Toa, Sierra de Sagua-Baracoa); 2) Cuenca Guantánamo; 3) Sistema de Cuencas Cauto-Nipe; y 4) Sistema de Levantamientos CamagüeyHolguín. MAKAROV \& FORMELL (1989) identifican un alineamiento NO$\mathrm{SE}$, que se denominó purial. Este elemento ha sido representado también en varios trabajos, que le han considerado: 1) una zona sismogeneradora Purial (Longitud (km) 100 y Ancho (km) 3-5); 2) un límite entre mesobloques; y 3) una estructura similar a la falla Baconao. Posteriormente, HERNÁNDEZ et al. (1990) sostienen que Guantánamo está compuesto, en un perfil S-N, por: 1) 3 grandes morfoestructuras sub-latitudinales: a) montañosa suroriental (Sierra Maestra); b) depresiones Graben superpuestas (Central y Guantánamo); y c) montañosa nororiental (Nipe-CristalSagua-Baracoa-Purial); y 2) las unidades de orden menor (mesobloques) son en cantidad: A) 6 ; B) 15 ; y C) 2 . Es decir, se considera que Cuba Oriental es una estructura neotectónica fragmentada, con independencia de las denominaciones.

Consideramos que el mapa morfoestructural de Cuba (GONZÁLEZ et al., 2003) (Fig. $10 \mathrm{~A})$ tiene la mejor visualización de las mayores estructuras de Cuba Oriental, algunas ya mencionadas. En la figura 2A se señalan aquellas localizadas en la zona de Guantánamo. Las 4 fotos que acompañan al mapa permiten apreciar la diferenciación de las formas del relieve interior y costero. Se han identificado, cartografiado y caracterizado 4 regiones peculiares de las costas con arcos cóncavos de Cuba Oriental (RP1= Holguín; RP2= Moa; RP3= Maisí; y RP4= Baracoa-SAS). Están indicadas 4 zonas del interior de Guantánamo con fuertes inflexiones $\left(\sim 90^{\circ}\right)$ en los cursos fluviales (1= Los Llanos; $2=\mathrm{S}$ de Cuchillas de Baracoa; 3= Río Yumurí; y 4= Jaguaní). A su vez, la figura 2B recoge un conjunto de elementos lineales del relieve: 1) el escarpe S-N entre Punta Caleta y Punta del Fraile; 
2) la alineación de algunos segmentos; 3) las direcciones del drenaje superficial; y 4) la organización de las terrazas costeras.

Para la evaluación sismotectónica de Cuba Oriental nos apoyamos en: BABAEV et al. (1989); BENFORD et al. (2012A, B); COMISIÓN AD HOC (1991); COTILLA (2014A, 2011, 2007, 2003, 1999, 1998A, B, C, D, 1993); COTILLA \& ÁlVAREZ (1999, 1991); COTILLA \& CÓRDOBA (2011A, B, 2010B, C, 2008); COTILLA \& FRANZKE (1999, 1994); COTILLA \& UDÍAS (1999A, B); COTILLA et al. (2007, 1998, 1997A, B, 1996A, 1991B, C, 1988); DEMETS \& WIGGINGS-GRANDISON (2007); MANN et al. (1995); MOLNAR \& SYKES (1969); ORBERA (1980); RODRÍGUEZ INFANTE et al. (2000, 1996); y RUBIO et al. (1994). Así consideramos que Cuba y La Española son neo-estructuras (megabloques) relacionadas espacial, temporal y energéticamente. Por lo tanto, para realizar un estudio sismotectónico adecuado es necesario distinguir que es Cuba Oriental la zona con mayor vinculación a La Española. Así hemos comentado que Cuba Oriental está al N del límite de placas (en la placa Norteamérica), mientras que La Española está en la zona límite de placas (placa Caribe) (Fig. 4A). Por ende, tienen significativas diferencias morfoestructurales.

En la figura 6B aparece el mapa de zonas sismogeneradoras elaborado por una comisión de expertos cubanos (en diversos campos científicos) (COMISIÓN AD HOC, 1991). Ese modelo se discute ampliamente en COTILLA (1993, 1998A y 1999) y sobre esa base sólo merece ser mencionado. Con idéntico propósito comentamos que CUEVAS (1998) determinó en Cuba Oriental un total de 6 anomalías isostáticas residuales: 1) Levingstone; 2) MoaNicaro; 3) Sierra Cristal; 4) Yateras; 5) Sabana la Mar (San Antonio del Sur); y 6) Sierra Maestra. De nuestro interés son las Nos. 2, 3, 4 y 5. También propuso un total de 7 zonas de magnitudes máximas, de los terremotos, a partir del estudio de la información isostática. COTILLA et al. (1996B) también descartan este resultado.

En la figura 10 están indicadas para Cuba Oriental: A) 13 zonas anómalas del relieve; B) la zona con fuerte actividad sísmica al S de la Sierra Maestra sobre la fosa de Oriente; C) zonas de drenaje N-S, muy corto, de Sierra Maestra y Sierra de Purial; y D) un conjunto de fallas y alineaciones. Esto permite confirmar su heterogeneidad y diferenciación morfoestructural contemporánea, destacando la mayor actividad del sector N y NE de Guantánamo con respecto al $\mathrm{S}$.

\section{DISCUSIÓN Y CONCLUSIONES}

El límite de las placas Caribe-Norteamérica es una estructura heterogénea de $1^{\text {er }}$ orden (Fig. 4A). Este límite en el segmento de Cabo Cruz-Punta de Quemado (falla Oriente) exhibe a lo largo de la costa $\mathrm{S}$ de Cuba, diferencias significativas en cuanto a: 1) hipsometría, morfología y características neotectónicas; 2) representación en los campos gravimétrico, isostático y magnético;3) actividad sísmica; 4) presencia de sectores con marcadas influencias transpresivas y transtensivas; y 5) tipos y combinaciones de estructuras secundarias asociadas. Así, se han identificado y caracterizado, de O-E, 4 zonas: 1) Cabo Cruz-Pilón; 2) Pilón-Baconao (donde está el mayor gradiente del relieve del Caribe); 3) Baconao-Bahía de Guantánamo; y 4) Bahía de Guantánamo-Punta de Quemado.

Se puede asegurar que Guantánamo: 1) tiene una definida diferenciación morfotectónica dentro de Cuba Oriental; 2) no tiene paleosismo-dislocaciones; 3) nunca ha sufrido un fuerte terremoto; 4) la actividad sísmica es menor que en Santiago de Cuba; 5) los mecanismos focales son diferentes con respecto al segmento de Santiago de Cuba; 6) no ha tenido tsunamis; 7) el sistema morfoestructural de la costa es diferente en 
las partes septentrional y meridional; 8) tiene varias zonas con anomalías neotectónicas (COTILLA et al., 1991D); 9) la densidad de fracturas en la Bahía de Guantánamo es menor con relación a la Bahía de Santiago de Cuba; 10) hay 5 zonas con anomalías significativas del relieve $(\mathrm{Za} 1=$ Baracoa, $\mathrm{Za} 2=$ Moa, $\mathrm{Za} 4=$ Cuchillas de Toa, Za5= San Antonio del Sur, y Za6= Guantánamo); y 11) tiene 4 tipos morfoestructurales: II-3, II-4, II-5 y III-5 (Fig. 10).

La figura 2A incluye 2 fotos del relieve y de los tipos de costa de Guantánamo. En ellas se aprecian muy bien los procesos abrasivos, $\mathrm{y}$ los elementos del relieve costero emergido. Hay otras 3 fotos que contienen evidencias de la tectónica activa. En una se observa un tramo del recorrido del Río Toa con los cortes que ha labrado en un territorio con tendencia al levantamiento intenso. Hay otra foto que nos muestra las fracturas del relieve en forma perpendicular al curso fluvial. La última foto recoge algunos de los procesos de tipo gravitacional por las fuertes pendientes. Hay 2 bloques deprimidos o hundidos en la costa $\mathrm{N}$ de Cuba Oriental: 1) Bahía de Nipe-Sagua de Tanámo; y 2) Cabacú-Mata. Este último colinda con el ya mencionado Escarpe de Maisí.

Aparentemente, las características morfoestructurales y neotectónicas de Guantánamo y del NO de Haití (península) son prácticamente las mismas (figs. $2 \mathrm{~B}$ y 11B). Esas 2 regiones distan $\sim 170 \mathrm{~km} \mathrm{y}$ están separadas por el Paso de los Vientos. En este sentido se conocen los valores $\left(\mathrm{km}^{2}\right)$ de las áreas de: 1) Punta de Maisí= 2.700; y 2) del Norte de Haití= 3.800. Las dimensiones lineales de la Península $\mathrm{N}$ de Haití son: 1) $\mathrm{O}-\mathrm{E}=19,7 \mathrm{~km}$; y 2) $\mathrm{N}-\mathrm{S}=23,5$ $\mathrm{km}$. Esas regiones tienen la misma tipología litológica en las terrazas costeras, pero las deformaciones de las terrazas costeras y los elementos fluviales observados en Haití no se determinaron en Guantánamo. Desde la perspectiva geodinámica están localizados en 2 placas diferentes, Guantánamo en la de Norteamérica y Haití en la del Caribe. En consecuencia, tienen sentido de movimiento diferente. La actividad sísmica es muy diferente, siendo muy superior en Haití, donde hasta la fecha no se han determinado sismo-dislocaciones. Por consiguiente, esto descarta, absolutamente, la existencia de dichas estructuras en el entorno de San Antonio del Sur. De hecho, en el tramo Cabo Cruz-Baconao no hay esas formas, a pesar de la muy superior actividad sísmica.

A) Esquema morfoestructural (GONZÁLEZ et al., 2003).

Aparecen: 1) tipos principales de morfoestructuras (montaña, altura y llanura); 2) las zonas morfoestructurales (I-1 $=$ meseta de Cabo Cruz, I-2= premontañas septentrionales, $\mathrm{I}-3=$ montañas bajas de la Sierra Maestra, I-4= Sierra del Turquino, I-5= premontañas meridionales, I-6= cuenca de Santiago de Cuba, $\mathrm{I}-7=$ macizo montañoso de la Gran Piedra; II-1= premontañas septentrionales, II- $2=$ mesetas de las sierras de Nipe y del Cristal, II-3= montañas bajas de las sierras de Mica y Moa, II-4= montañas bajas de las Cuchillas de Toa y Baracoa, II-5= macizo montañoso del Purial, II-6= meseta de Maisí; III-1 = llanura aluvial del Cauto, III-2 = llanura central y mesetas, III$3=$ altura de Cacocúm, III-4= llanura costera de Nipe; IV-1= altura de Gibara); 3) alineaciones principales del relieve (línea negra gruesa discontinua); 4) zonas anómalas del relieve (círculos, Za1); 5) zonas de fallas (líneas negras); 6) localidades $(\mathrm{BA}=$ Baracoa, $\mathrm{BG}=$ Bahía de Guantánamo, BNI= Bahía de Nipe, BSC= Bahía de Santiago de Cuba, $\mathrm{BST}=$ Bahía de Sagua de Tánamo, $\mathrm{CB}=$ Caletón Blanco, $\mathrm{CC}=\mathrm{Cabo} \mathrm{Cruz}, \mathrm{MP}=$ Marea de Portillo, $\mathrm{PC}=$ Punta Caleta, $\mathrm{PQ}=$ Punta de Quemado, $\mathrm{PT}=$ Pico Turquino); 7) zona de fuerte actividad sísmica y gradiente intenso del relieve (estrellas grises); 8) fotos (Uvero, Siboney, Imías-Cajobabo Maisí, Toa, y Cauto [1) niveles altimétricos (N1, $\mathrm{N} 2$, N3 y N4); 2) $\mathrm{BC}=$ bloques caídos; 


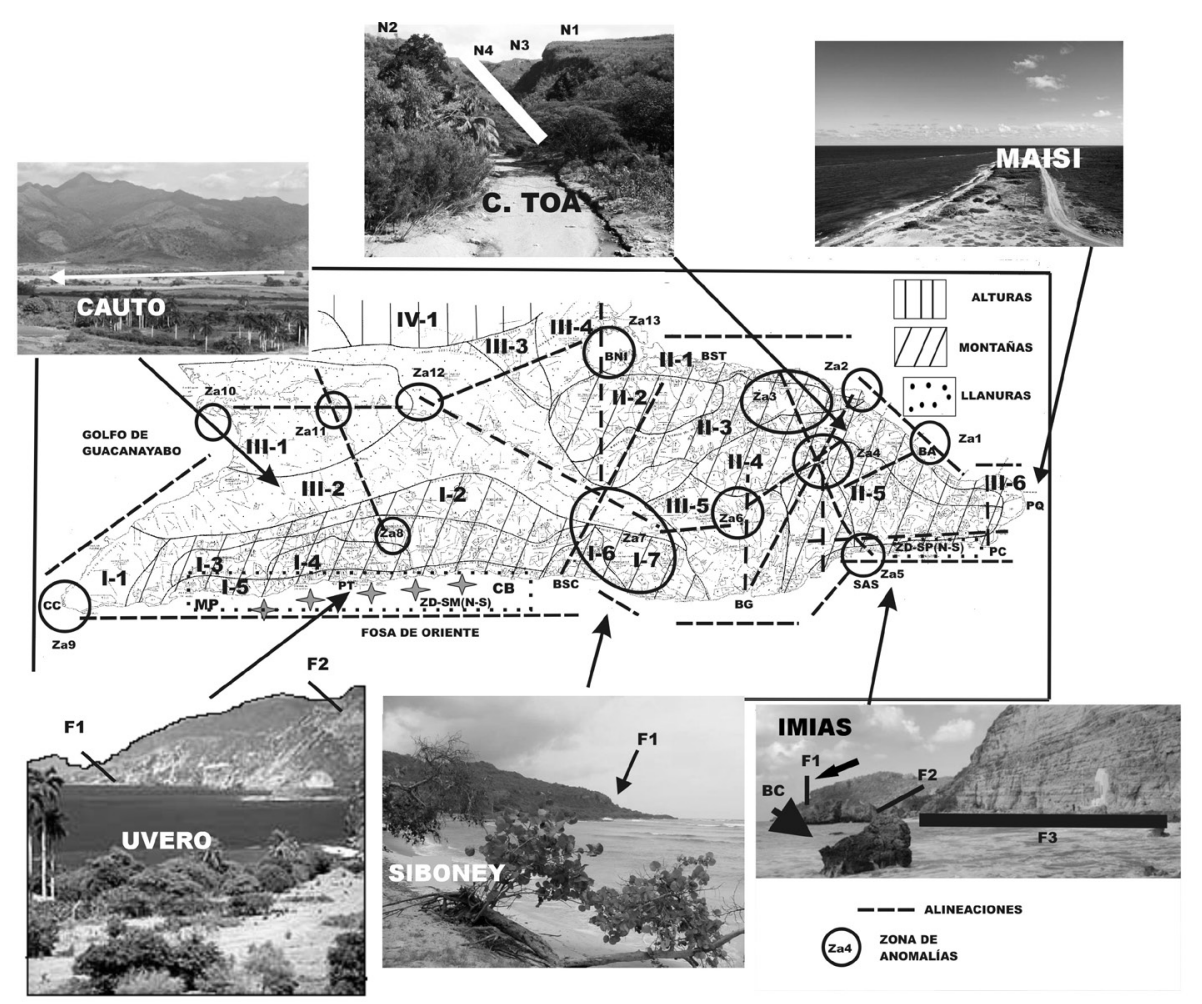

Fig. 10. Mapa morfoestructural de Cuba Oriental.

Fig. 10. Morphostructural map of Eastern Cuba.

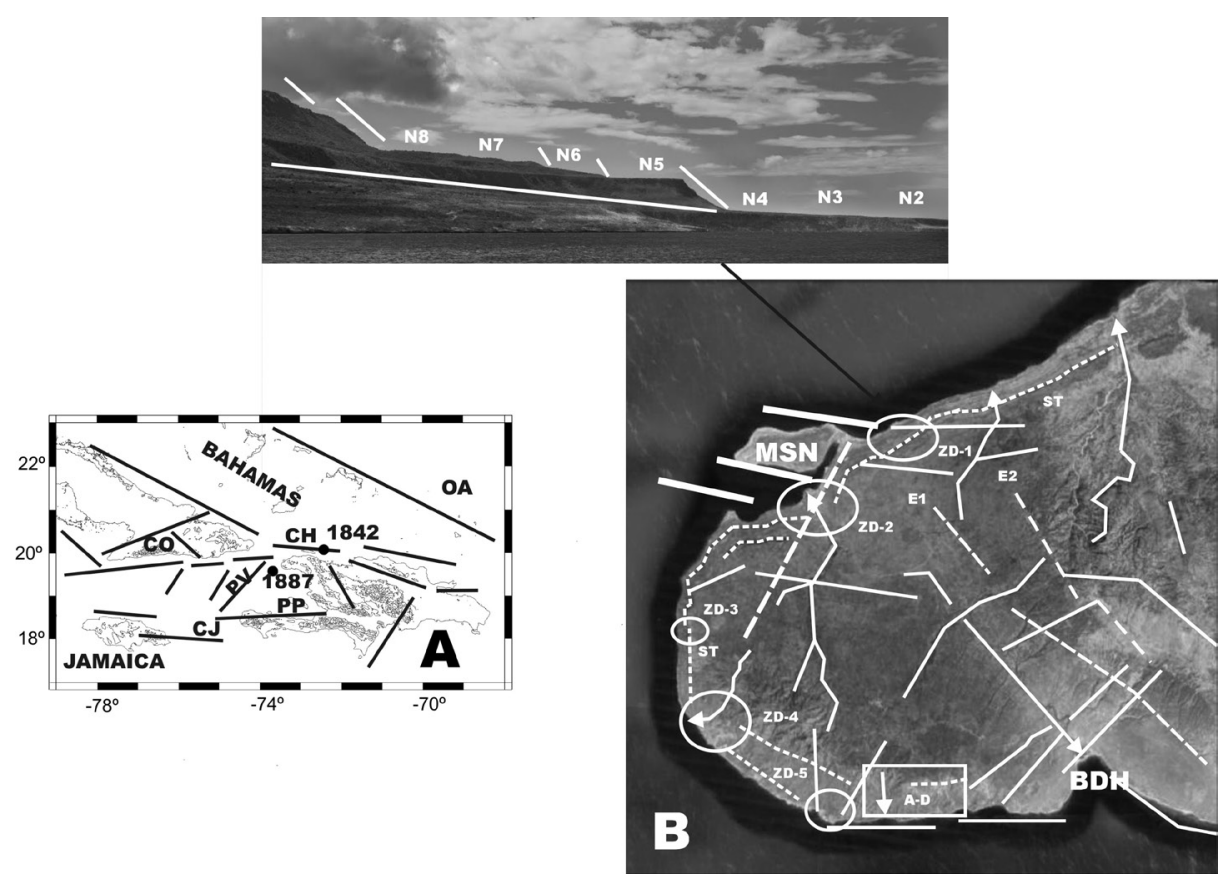

Fig. 11. Elementos morfotectónicos en el Caribe Septentrional.

Fig. 11. Morphotectonic elements in the Northern Caribbean. 
3) fracturas-fallas (líneas negras, F1, F2 y F3); 4) basculamiento (flecha gruesa negra)]); 9) zona de drenaje N-S (rectángulos con puntos, ZD-SM(N-S)= Sierra Maestra, ZD-SP(N-S) $=$ Sierra de Purial).

A) Alineaciones principales del CaribeCuba-Haití.

Aparecen: 1) localidades $(\mathrm{CH}=\mathrm{Cabo}$ Haitiano, $\mathrm{CO}=$ Cuba Oriental, $\mathrm{GO}=$ Gonave, $\mathrm{LE}=\mathrm{La}$ Española, $\mathrm{PDP}=$ Port de Paix, $\mathrm{PP}=$ Puerto Príncipe, $\mathrm{CJ}=\mathrm{Canal}$ de Jamaica, $\mathrm{OA}=$ Océano Atlántico, $\mathrm{PV}=$ Paso de los Vientos); 2) alineaciones; 3) terremotos fuertes $(1842(\mathrm{M}=8,2)$ y $1887(\mathrm{M}=7,9)$, círculos negros $)$.

B) Alineaciones principales del $\mathrm{NO}$ de Haití.

Aparecen: 1) localidades (BDH= Bahie de Henne, MSN= Mole Saint Nicolas); 2) alineaciones (líneas continuas); 3) escarpes (líneas discontinuas (E1)); 4) Sistema de terrazas costeras (línea de puntos (ST)); 5) corrientes fluviales con sentido de drenaje; 6) zonas de deformación costera (círculos ZD-1); 7) zona de deformación costera principal (rectángulo); 8) foto (sistema de niveles costeros con fracturas (ST)).

El Paso de los Vientos es el enlace y también la separación física entre Cuba Oriental y el N de Haití. Desde el punto de vista neotectónico puede interpretarse de 2 formas, pero consideramos que la mejor fue representada por MANN \& BURKE (1980). Esa zona diferencia, muy bien, la actividad sísmica de Cuba Oriental y del $\mathrm{N}$ de Haití. En el entorno inmediato de
Haití han ocurrido al menos 2 terremotos fuertes (1842 y 1887) (Fig. 11A), pero en Cuba Oriental el mayor nivel de actividad sísmica está al $\mathrm{O}$ de Baconao y hasta Cabo Cruz (Fig. 4B); no incluye a Guantánamo. En este último sitio, la sismicidad reciente no muestra tampoco un alto nivel. En la figura 11B destacan: 1) las bruscas y pronunciadas inflexiones de los sistemas de terrazas y escarpes costeros (indicados con 5 círculos y un rectángulo); 2) el sistema de alineaciones y fallas predominantes; y 3 ) las modificaciones de los cursos fluviales.

En el N del Caribe está también el Estrecho de La Mona $(\sim 260 \mathrm{~km})$, entre las islas de La Española y Puerto Rico (Fig. 5B). Esas 2 neo-estructuras (megabloque $\mathrm{y}$ macrobloque, respectivamente) están localizadas en 2 microplacas diferentes, aunque en el Estrecho de La Mona y sus entornos adyacentes al E y O (República Dominicana y Puerto Rico) se han producido eventos sísmicos fuertes $\mathrm{y}$ tsunamis (COTILLA \& CÓRDOBA, 2011B). El estrecho antes mencionado se caracteriza por: 1) ser el encuentro de fallas activas de direcciones E-O y SO-NE; 2) tener morfoestructuras de categorías II y III; 3 ) poseer 2 frentes de subducción en sus inmediaciones relacionadas con las fosas de Muertos ( 4.500 m) y Puerto Rico ( $~ 8.800$ $\mathrm{m})$; y 4) tener los mismos tipos litológicos en las costas y terrazas. Es decir, el Paso de los Vientos y el Estrecho de La Mona son áreas equivalentes y estructuras neotectónicas de enlace del $\mathrm{N}$ del Caribe, pero la del Paso de los Vientos es una zona prácticamente sin actividad sísmica, por lo que resulta ser una "anomalía" dentro de un sistema de fallas activas del límite de placas. 


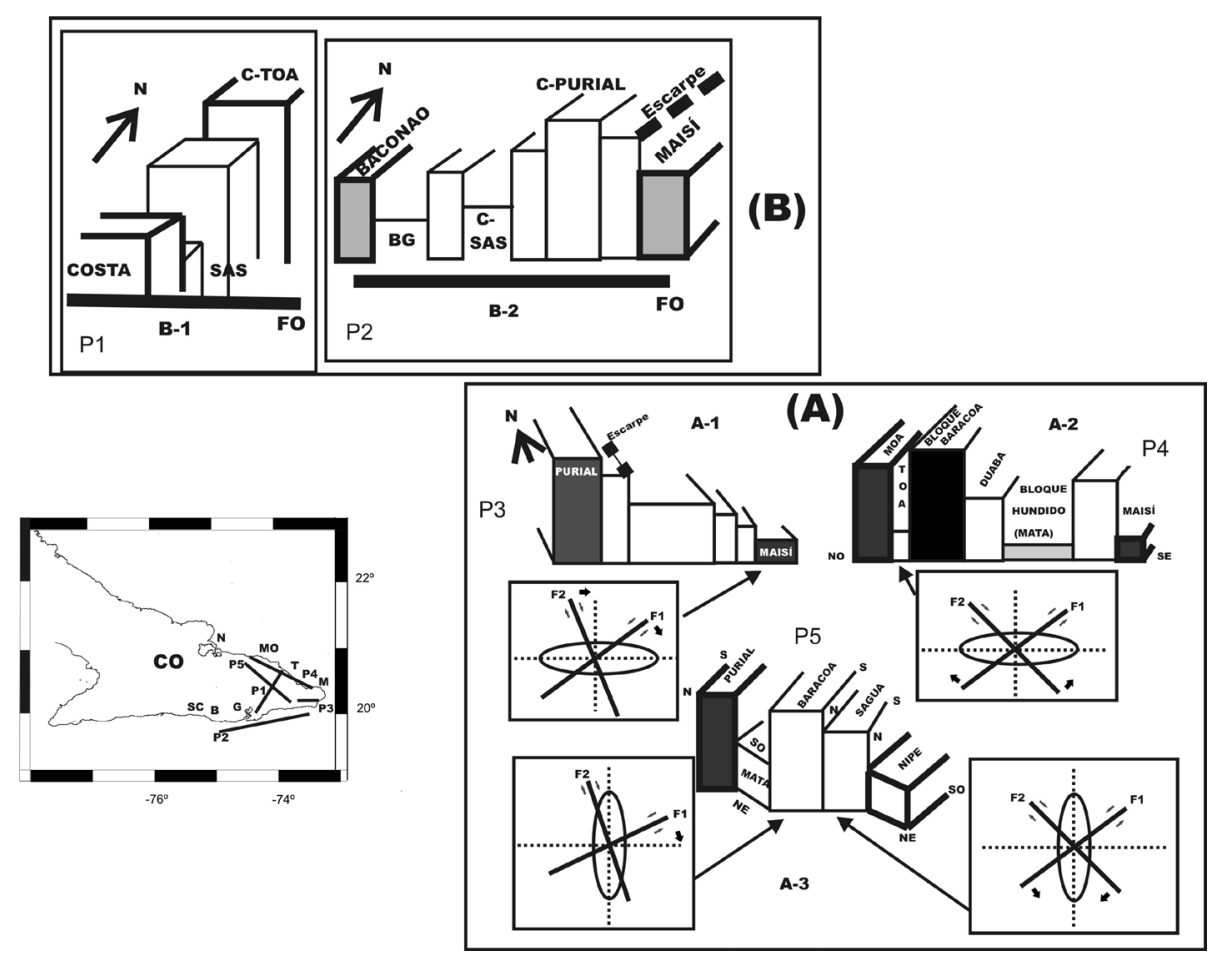

Fig. 12. Sistemas de bloques de Cuba Oriental.

Fig. 12. Blocks' systems of Eastern Cuba.

Recuadro que indica los perfiles (P1-P5) de las figuras A y B.

A) Costa norte.

Aparecen: 1) tres cortes o transectos: A-1) Purial-Maisí; A-2) Moa-Maisí; A-3) Purial-Nipe; 2) sistema de bloques; 3) elipse de deformación; 4) fallas (F1, F2); 5) sentido de movimiento y desplazamiento (flechas grises y negras).

B) Costa sur.

Aparecen: 1) dos cortes o transectos: B-1) línea de costa-Cuchillas de Toa; B-2) Baconao-Maisí; 2) sistemas de bloques.

Es conocido que los datos sobre los esfuerzos muestran que: A) a escala planetaria están decididos por la tectónica de placas; B) la orientación de los esfuerzos tectónicos, para un lugar determinado, puede diferir en cuanto a las mediciones medias y los estimados de los esfuerzos regionales. Evidentemente, esto responde a la presencia de estructuras locales y a las heterogeneidades de la corteza. Incluso, a menor escala, las modificaciones de los esfuerzos pueden ser significativas, pero, con el análisis y el procesamiento de las medidas de campo se puede lograr una clasificación adecuada para los marcos local y regional. Es decir, el estudio de las microestructuras siempre permite identificar su relación con las macro-estructuras.

Así nuestros trabajos de campo en Cuba Oriental muestran que las fallas activas (Baconao, Nortecubana, Purial y Oriente) como estructuras geológicas están segmentadas. Para nuestras investigaciones definimos localidades de aproximadamente 
1-5 km, donde detallamos áreas de decenas de metros, y consideramos distancias entre localidades de pocos cientos de metros a un kilómetro. Como primer resultado tenemos que las zonas sísmicamente más activas están donde hay cruce de fallas y fracturas.
Estas características se recogen en las figuras $12 \mathrm{~A}$ y B. En ellas también están representados los bloques delimitados en Guantánamo y sus sentidos de movimiento, así como las elipses deformación a ellos asociadas.

PLACA DE NORTEAMÉRICA
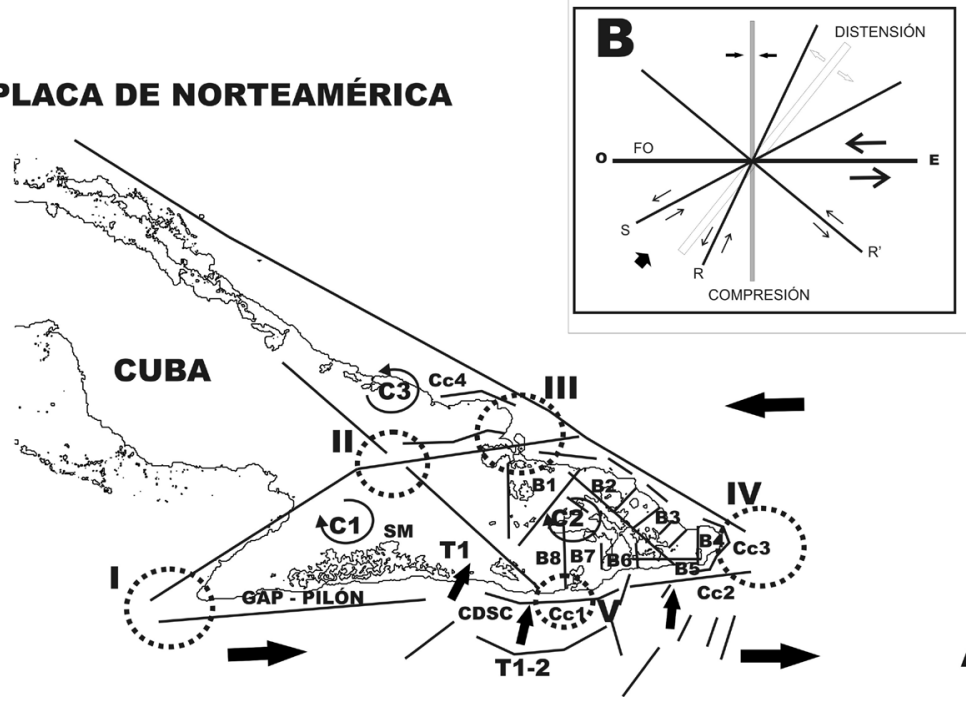

Fig. 13. Cinemática neotectónica de Cuba Oriental.

Fig. 13. Neotectonic kinematic of Eastern Cuba.

A) Morfoestructuras principales.

Aparecen: 1) localidades $(\mathrm{BG}=$ Bahía de Guantánamo, $\quad \mathrm{CDSC}=$ Cinturón Deformado de Santiago de Cuba, $\mathrm{SM}=$ Sierra Maestra); 2) alineaciones principales (líneas negras); 3) zonas curvas y arqueadas (líneas curvas: $\mathrm{Cc} 1=$ Guantánamo, Cc2= Caleta, Cc3= Maisí, Cc4= Holguín); 4) bloques activos principales $(\mathrm{B} 1=$ Sagua, $\mathrm{B} 2=$ Moa, $\mathrm{B} 3=$ Baracoa, B4= Maisí, B5= Imías, B6= San Antonio, B7 = Bahía de Guantánamo, B8= O de Guantánamo); 5) tensor de esfuerzos (T1= Santiago de Cuba, T12= Guantánamo: flecha gruesa-corta); 6) sentido de movimiento de las placas (flechas grandes negras); 7) zonas de articulación de morfoestructuras (círculos de puntos (I));8) tendencias de movimiento de los bloques (flechas curvas: $\mathrm{C} 1=$ Sierra Maestra, $\mathrm{C} 2=$ NipeBaracoa-Purial, C3= Gibara-Holguín).
B) Modelo de Riedel para Guantánamo.

Se presentan: $\mathrm{FO}=$ Falla Oriente, $\mathrm{R}=$ Riedel, $\mathrm{R}^{`}=$ Conjugada, $\mathrm{S}=$ Shear, estructuras (compresión y distensión).

De otra parte existe un método propuesto y probado, de RIVERA \& CISTERNAS (1990), para determinar al tensor desviador R. Éste es un parámetro de tipo escalar que representa sintéticamente la forma del elipsoide de esfuerzos de una región, a partir de los datos de los focos de terremotos. Así, su forma está dada por: $\mathrm{R}=(\sigma \mathrm{z}-\sigma \mathrm{x}) /(\sigma \mathrm{y}$ $-\sigma x)$ pero con la condición $\sigma y \geq \sigma x$. Esto ha permitido determinar y clasificar, por vez primera, el estado de los esfuerzos del Caribe N, con 4 valores (R1, R2, R1-2 y R3) que se asocian a 4 zonas de mecanismos focales (Fig. 5A). Las zonas son: la 1- R1 que corresponde a cizalla $(\mathrm{R}<1)$, la $4-\mathrm{R} 2$ que se asocia a compresión uni-axial $(\mathrm{R}<$ 
$0)$, la 3- R3 que es del tipo de extensión triaxial $(\mathrm{R}=1)$ y la 2- $\mathrm{R} 1-2$ que combina la cizalla y la compresión uni-axial. Este es el segmento donde encaja Guantánamo.

COTILLA \& ÁLVAREZ (1998) sostienen que las franjas de mayor amenaza geológica (Grado I) están fuera de los límites de Cuba y que en el sector del Caribe hay Grado II. Aseguran que los grados: 1) III están en el $\mathrm{N}$ de La Española; 2) IV en la zona $\mathrm{S}$ de Cuba Oriental, entre Pilón y Baconao; y 3) V en Cuba Oriental. Así, el Esquema de Amenaza Geológica de Cuba (Fig. 11 de COTILLA \& ÁlVAREZ, 1998) para su parte oriental tiene 5 zonas de nivel muy fuerte (Baracoa, Nipe, Santiago de Cuba, Sierra Maestra y Sierra de Purial) en un fondo de fuerte a moderado (donde está la mayor parte de la provincia Guantánamo). También resaltan 3 niveles para las líneas de debilidad tectónica actual (Oriente $=$ muy alto; y Nortecubana y Cauto-Nipe= altos). Esos apuntes, evidentemente, confirman nuestros resultados.

Por último, la figura 13A contiene el principal resultado morfotectónico para Guantánamo. En ella se: 1) aprecia la complejidad de la zona $\mathrm{N}$ y $\mathrm{NE}$ con respecto a la $\mathrm{S}$, lo que se corresponde muy bien con la actividad sísmica reciente (periodo 1992-1999); 2) representan: A) los sentidos de movimiento predominante de las placas del Caribe y de Norteamérica, que evidentemente afectan y condicionan la actividad de Cuba Oriental; B) 3 celdas geodinámicas $(\mathrm{Cl}=$ Sierra Maestra; $\mathrm{C} 2=$ Nipe-Baracoa-Purial; y C3= Holguín) de la Unidad Neotectónica Oriental; C) 5 zonas de articulación de las principales fallas activas ( $\mathrm{I}=\mathrm{Cabo} \mathrm{Cruz}$; II= San Germán; III= Nipe; IV= Maisí; y $\mathrm{V}=$ Baconao-Guantánamo); D) 2 tensores de esfuerzos estimados en Cuba Oriental y Guantánamo; y E) los bloques y sus límites en el sector de Guantánamo, en C2. El modelo con la segmentación de las fallas se condiciona a la representación de RIEDEL (1929) (Fig. 13B).

\section{AGRADECIMIENTOS}

Este trabajo se realizó en el Departamento de Física de la Tierra, Astronomía y Astrofísica 1. Amador García Sarduy preparó todas las figuras. Esta investigación ha sido parcialmente financiada con 4 proyectos: TSUJAL (CGL201129474-C02-01), CARIBENORTE (CTM2006-13666-C02-02), TOPOIBERIA (CSD2006/0041) y GR35/10-A/910549. La idea original de esta tarea científica fue discutida y analizada en la década de los años 90 con los colegas alemanes Joachim Pilarski y Hans Joachim Franzke.

\section{REFERENCIAS}

\section{ACADEMIAS DE CIENCIAS DE CUBA} \& HUNGRÍA, 1981. Levantamiento geológico de las provincias orientales, escala 1:250.000. Instituto de Geología y Paleontología.

AHORNER, L., 1975. Present-day stress field and seismotectonic block movements along major fault zones in Central Europe. Tectonophysics, 29: 233-249.

Állarez, L. \& T.J. CHUY, 1992. Peligrosidad sísmica de Cuba. Una aproximación a la regionalización sísmica del territorio nacional. Revista Geofísica, 35: 125-150.

ÁLVAREZ, L., F. VACCARI \& G.F. PANZA, 1999. Deterministic seismic zoning of eastern Cuba. Pure appl. geophys., 156: 469-486.

ÁLVAREZ, L., G.F. PANZA, F. VACCARI \& B.E. GONZÁLEZ, 2001. Modeling of seimic ground motion in Santiago de Cuba city from earthquakes in Oriente fault seismic zone. Pure appl. geophys., 158: 1763-1782.

Álvarez, L., M. COTILla \& T. CHUY, 1990. Informe final del tema 430.03: Sismicidad de Cuba. En: Archivo 
del Departamento de Sismología, Instituto de Geofísica y Astronomía, Academia de Ciencias de Cuba.

ÁlVAREZ, L., M. RUBIO, T. CHUY \& M. COTILLA, 1985. Informe final del tema de investigación 31.001: Estudio de la sismicidad de la región del Caribe y estimación preliminar de la peligrosidad sísmica en Cuba. En: Archivo del Departamento de Sismología, Instituto de Geofísica y Astronomía, Academia de Ciencias de Cuba.

ÁlVAREZ, L., M. SERRANO, M. RUBIO, T. CHUY \& B. GONZÁLEZ, 1984. El terremoto del 19 de febrero de 1976. Pilón, región oriental de Cuba. Revista Investigaciones Sismológicas en Cuba, 5: 5-60.

ALEKSEEVSKAYA, M., A. GABRIELOV, I. GUELFAND, A. GVISHIANI \& E. RANTSMAN, 1977. Formal morphostructural zoning in mountain territories. J. Geophys. Res., 43: 227-233.

ARSENIEV, Y.M., G. CAPOTE \& S.N. KAKASHOV, 1983. Esquema cosmo-fototectónico de Cuba, escala 1:500.000. Centro de Investigaciones Geológicas, Ministerio de la Industria Básica.

ARTEAGA BARRIOS, F., 1989. Mapa de morfoestructuras submarinas. En: Nuevo Atlas Nacional de Cuba, IV Relieve, IV.3.1.

ASSINOVSKAYA, B.A. \& S.L. SOLOVYEV, 1994. Definition and description of the sources zone of potential earthquakes in the Barents Sea. Physics of the Solid Earth, 29(8): 664-675.

BABAEV, A., V. TOKARIOV, L. LYSKOV \& L. ORBERA, 1989. Informe de las investigaciones geólogo-tectónicas del territorio de Cuba Oriental y de la región de emplazamiento de las áreas $\mathrm{N}^{\mathrm{o}} 2$ y 10 de la CEN Holguín. Tomo I, Libro 3, Parte I/1. Archivo de la UPI-CEN Holguín. Ministerio de la Industria Básica.
BANKWITZ, P., G. SCHNEIDER, H. KÄMPF \& E. BANKWITZ, 2003. Structural characteristics of epicentral areas in Central Europe: Study case Cheb Basin (Czech Republic). J. Geodynamics, 35: 5-32.

BENFORD, B., C. DEMETS \& E. CALAIS, 2012A. GPS estimates of microplate motions, northern Caribbean: evidence for a Hispaniola microplate and implications for earthquake hazard. Geophys. J. Int., 191: 481-490.

BENFORD, B., C. DEMETS, B. TIKOFF, P. WILLIAMS, L. BROWN \& M. WIGGINS-GRANDISON, 2012B. Seismic hazard along the southern boundary of the Gonave microplate: Block modelling of GPS velocities from Jamaica and nearby islands, northern Caribbean. Geophys. J. Int., 190: 59-74.

BLANCO, J. \& J. PROENZA, 1994. Terrenos tectono-estratigráficos en Cuba Oriental. Revista Minería y Geología, 11: 11-18.

BRESZNYÁNSZKY, K., G. FRANCO \& G. RADOCZ, 1983. Perfiles comparativos de las áreas de Cabo Cruz y Maisí. En: E. Nagy (Editor). Contribución a la geología de Cuba Oriental. Editorial CientíficoTécnica, La Habana, 169-172 pp.

BOVENKO, V.G., B. Y. E SCHENKOVA \& G. HERNÁNDEZ, 1980. New geophysical data on the deep structure of eastern Cuba. Sov. Geol., 9: 101-109.

BUSH, V. \& I. SHERBAKOVA, 1986. New data on the deep tectonics of Cuba. Geotectonics, 20(3): 192-203.

BUSTO, R. DEL., 1975. Las terrazas marinas de Maisí. Serie Geografía, 7: 1-12.

CALAIS, E. \& B. MERCIER DE LEPINAY, 1995. Strike-slip tectonic processes in the northern Caribbean between Cuba and Hispaniola. Mar. Geophys. Res., 17: 63-95. 
CALAIS, E. \& B. MERCIER DE LÈPINAY, 1993. Semiquantitative modeling of strain and kinematics along the Caribbean / North America strike-slip. Plate Boundary Zone. J. Geophys. Res., 98: 8293-8308.

CALAIS, E. \& B. MERCIER DE LÈPINAY, 1991. From transpression along the northern Caribbeab plate boundary off Cuba: implications for the recent motion of the Caribbean plate. Tectonophysics, 186: 329-350.

CALAIS, E. \& B. MERCIER DE LÉPINAY, 1990. A natural model of active transpressional tectonics: The echelon structures of the Oriente Deep, along the northern Caribbean transcurrent plate boundary. Rev. Fr. Pét., 45: 147-160.

CALMUS, T., 1986. La frontera de las placas Norteamérica y Caribe. Estructuras principales y evolución Cenozoica. Bol. Dpto. Geol. Universidad de Sonora, 3(1): 19-37.

CAMPOS DUEÑAS, M., 1983. Rasgos principales de la tectónica de la porción oriental de las provincias de Holguín y Guantánamo. Revista Minería y Geología, 2.

CASE, J.E., T.L. HOLCOMBE \& R.G. MARTIN, 1984. Map of geologic provinces in the Caribbean region. Geol. Soc. Am. Memor., 162: 1-31.

CHUY, T., 1980. Régimen sísmico de la región suroriental de Cuba. Revista Investigaciones Sismológicas en Cuba, 1: 58-68.

COBIELLA, J.L., 1983. Algunas consideraciones sobre el origen de la fosa de Bartlett. Revista Minería y Geología, 1: 29-56.

COBIELLA, J.L. \& J. RODRÍGUEZ, 1986. Sobre la edad de la fosa de Bartlett (Caimán) y la magnitud de los desplazamientos horizontales de la placa del Caribe de acuerdo con los datos geológicos del norte de Centroamérica. Revista Minería y Geología, 1: 15-30.
COBIELLA, J.L., F. QUINTAS, M. CAMPOS \& M. HERNÁNDEZ, 1984. Geología de la región oriental y suroriental de la provincia de Guantánamo. Revista Oriente, 125 pp.

COMISIÓN AD HOC, 1991. Dictamen de la Comisión Ad hoc para la determinación de las zonas sismogeneradoras de la región oriental y sus zonas adyacentes. En: Archivo del Departamento de Sismología, Instituto de Geofísica y Astronomía, Academia de Ciencias de Cuba.

COTILLA, M.O., 2014A. Alternative interpretation for the active zones of Cuba. Geotectonics, 48(6): 459-482.

COTILLA, M.O., 2014B. Cuban Seismology. Revista de Historia de América, 143: 43-98.

COTILLA, M.O., 2012. Historia sobre la Sismología del Caribe Septentrional. Revista de Historia de América, 147: 111-154.

COTILLA, M.O., 2011. ¿Tsunamis en Cuba? Revista Física de la Tierra, 23: 173-197.

COTILLA, M.O. Un recorrido por la Sismología de Cuba. Editorial Complutense, Madrid, 2007, ISBN 97-8-47- 491827-4.

COTILLA, M.O., 2003. The Santiago de Cuba earthquake of 11 June 1766: Some new insights. Geofísica Internacional, 42(4): 589-602.

COTILLA, M.O., 1999. La ciencia sismológica en Cuba (I). Consideraciones principales. Revista de Historia de América, 124: 29-54.

COTILLA, M.O., 1998A. Una revisión de los estudios sismotectónicos en Cuba. Revista Estudios Geológicos, 54(3-4): 129-145.

COTILLA, M.O., 1998B. Sismicidad y sismotectónica de Cuba. Revista Física de la Tierra, 10: 53-86. 
COTILLA, M.O., 1998C. Terremotos de Cuba. GEOS, 18(3): 180-188.

COTILLA, M.O., 1998D. An overview on the seismicity of Cuba. Journal of Seismology, 2: 323-335.

COTILLA, M.O. Una caracterización sismotectónica de Cuba. PhD Thesis, Instituto de Geofísica y Astronomía, Academia de Ciencias de Cuba, 1993. 200 p.

COTILLA, M.O. \& J.L. ÁlVAREZ, 1999. Mapa de zonas sismogeneradoras de Cuba. Geología Colombiana, 23: 97-106.

COTILLA, M.O. \& J.L. ÁLVAREZ, 1991. Zonas sismogeneradoras de CubaJamaica-La Española-Puerto Rico. En: Archivo del Departamento de Sismología, Instituto de Geofísica y Astronomía, Academia de Ciencias de Cuba, 10 p.

COTILLA, M. \& D. CÓRDOBA, 2011 A. Comments about tsunami occurrences in the northern Caribbean. En: Tsunamis. ISBN: 978-953-307-431-3.

COTILLA, M. \& D. CÓRDOBA, $2011 B$. Análisis morfotectónico de la Isla de Puerto Rico, Caribe. Revista Geofísica, 52: 79-126.

COTILLA, M. \& D. CÓRDOBA, 2010A. Determination of lineaments in Hispaniola. Revista Geográfica, 147: 133-154.

COTILLA, M. \& D. CÓRDOBA, $2010 B$. The Bayamo earthquake (Cuba) of the 18 October 1551. International Journal of Geosciences, 1: 1-13.

COTILLA, M. \& D. CÓRDOBA, $2010 \mathrm{C}$. The August 20, 1852 earthquake in Santiago de Cuba. Russian Geology and Geophysics, 51: 1227-1246.

COTILLA, M.O. \& D. CÓRDOBA, 2010D. Study of the Cuban fractures. Geotectonics, 44(2): 176-202.
COTILLA, M.O. \& D. CÓRDOBA, 2009. The Hispaniola fluvial system and its morphostructural context. Physical Geography, 30(5): 453-478.

COTILLA, M. \& D. CÓRDOBA, 2008. Notes on three earthquakes in Santiago de Cuba (14.10.1800, 18.09.1826, 07.07.1842). Russian Geology and Geophysics, 51: 243-251.

COTILLA, M.O.\& D. CÓRDOBA, 2003. Caracterización morfotectónica de Galicia, España. Revista Geofísica, 58: 5-56.

COTILLA, M.O. \& H.J. FRANZKE, 1999. Validación del mapa sismotectónico de Cuba. Boletín Geológico y Minero, 110(5): 573-580.

COTILLA, M.O. \& H.J. FRANZKE, 1994. Some comments on the seismotectonic activity of Cuba. Z. Geol. Wiss., 22(3/4): 347-352.

COTILLA, M.O. \& A. UDÍAS, 1999A. Geodinámica del límite CaribeNorteamérica. Rev. Soc. Geol. de España, 12(2): 175-186.

COTILLA, M.O. \& A. UDÍAS, 1999B. La ciencia sismológica en Cuba (II). Algunos terremotos históricos. Revista de Historia de América, 125: 45-90.

COTILLA, M.O., H.J. FRANZKE \& D. CÓRDOBA, 2007. Seismicity and seismoactive faults of Cuba. Russian Geology and Geophysics, 48: 505-522.

COTILlA, M.O., L. ÁlVAREZ \& M. RUBIO, 1997A. Sismicidad de tipo intermedio en Cuba. Revista Geología Colombiana, 22: 35-40.

COTILLA, M.O., L. ÁLVAREZ, T. CHUY \& O. PORTUONDO, 1988. Algunos criterios de la peligrosidad sísmica en Cuba (2). Algunos criterios sobre la peligrosidad 
sísmica en zonas de baja actividad del territorio de Cuba. Comunicaciones Científicas sobre Geofísica y Astronomía, 2, 19 p.

COTILLA, M.O., P. BANKWITZ, L. ÁLVAREZ, H.J. FRANZKE, M.F. RUBIO \& J. PILARSKI, 1998. Cinemática neotectónica de Cuba. Rev. Soc. Geol. de España, 11(1-2): 33-42.

COTILLA, M.O., P. BANKWITZ, H.J. FRANZKE, J.L. ÁLVAREZ, E.C. GONZÁLEZ, J.L. DÍAZ \& F. ARTEAGA, 1996A. Una valoración sismotectónica de Cuba. Revista Geofísica, 45: 145-180.

COTILLA, M.O., E.C. GONZÁlez, C.C. CAÑETE \& J.L. DÍAZ, 1991 A. Estudio complejo geomorfólogo-estructural de la zona marítima del sur de Cuba Oriental. Revista Geofísica, 34: 167-176.

COTILLA, M.O., E.C. GONZÁLEZ, C.C. CAÑETE, J.L. DÍAZ \& R. CARRAL, 2003. La red fluvial de Cuba y su interpretación morfoestructural. Revista Geográfica, 134: 23-50.

COTILla, M.O., G. MiLláN, L. ÁlVAREZ, D. GONZÁLEZ, M. PACHECO \& F. ARTEAGA, $1996 \mathrm{~B}$. Esquema neotectogénico de Cuba. Informe científico-técnico del Departamento de Geofísica del Interior. En: Archivo del Instituto de Geofísica y Astronomía, Academia de Ciencias de Cuba, 100 p.

COTILLA, M.O., P. BANKWITZ, H.J. FRANZKE, L. ÁlVAREZ, E. GONZÁLEZ,J.L.DÍAZ,G.GRÜNTHAL, J. PILARSKI \& F. ARTEAGA, 1991B. Mapa sismotectónico de Cuba, escala 1:1.000.000. Comunicaciones Científicas sobre Geofísica y Astronomía, 23, 35 p.

COTILLA, M.O., H.J. FRANZKE, J. PILARSKI, O. PORTUONDO, M. PILARSKI \& F. ARTEAGA, 1991C. Mapa de alineamientos y nudos tectónicos principales de Cuba, escala 1:1.000.000. Revista Geofísica, 35: 53-112.
COTILLA, M.O., E.C. GONZÁLEZ, H.J. FRANZKE, J.L. DÍAZ, F. ARTEAGA \& L. ÁlVAREZ, 1991D. Mapa neotectónico de Cuba, escala 1:1.000.000. Comunicaciones Científicas sobre Geofísica y Astronomía, 22, 37 p.

COTILLA, M.O., M. RUBIO, L. ÁLVAREZ \& G. GRÜNTHAL, 1997 B. Potenciales sísmicos del sector CentroOccidental del arco de las Antillas Mayores. Revista Geofísica, 46: 129-150.

CUEVAS OJEDA, J.L., 1998. Estudios sobre la isostasia en Cuba: Una caracterización y delimitación de zonas potencialmente sísmicas. Boletín Geológico y Minero, 109(3): 53-66.

\section{DEMETS, C. \& M. WIGGINGS-} GRANDISON, 2007. Deformation of Jamaica and motion of the Gonave microplate from GPS and seismic data. Geophys. J. Int., 168: 362-378.

DEMETS, C., R.G. GORDON \& D.F. ARGUS, 2010. Geologically current plate motions. Geophys. J. Int., 181: 1-80.

DEMETS, C., P.E. JANSMA, G.S. MATTIOLI, T. DIXON, P. FARINA, R. BILHAM, E. CALAIS \& P. MANN, 2000. GPS geodetic contraints on CaribbeanNorth American plate motion. Geophys. Res. Letters, 27: 437-440.

FLORES, R., G. MILLÁN, J.L. CHANG, C. PÉrez, E. CASTEllanos \& K. NÚÑEZ, 1998. Tectónica de Cuba Oriental. En: Geología y Minería, Memorias I, 3er Congreso de Geología y Minería, La Habana, 240-243 pp.

FRANCO, G.L., 1976. Texto explicativo del mapa geológico de la provincia de Oriente, escala 1:250.000. En: E. Nagy. Instituto de Geología y Paleontología, Ministerio de la Industria Básica, La Habana.

GATINSKY, Y. U. G \& D.V. RUNDQUIST, 2004. Geodynamics of Eurasia: Plate 
tectonics and block tectonics. Geotectonics, 38(1): 1-16.

GIUNTA, G., L. BECCALUVA \& F. SIENA, 2006. Caribbean plate margin evolution: Constraints and current problems. Geologica Acta, 4(1-2): 265-277.

GONZÁLEZ, E.C., C.C. CAÑETE, J.L. DÍAZ, L. PÉREZ \& M.O. COTILLA, 1989A. Esquema morfoestructural de Cuba, escala 1:250.000. Revista Geología y Minería, 1: 16-34.

GONZÁLEZ, E.C., C. CAÑETE PÉREZ, J.L. DÍAZ COMESAÑAS, L. PÉREZ TAMAMES \& M. COTILLA RODRÍGUEZ, 1989B. Esquema neotectónico de Cuba. Serie Geológica, 1: 16-34.

GONZÁLEZ, E.C., M.O. COTILLA, C.C. CAÑETE, J.L DÍAZ, R. CARRAL \& F. ARTEAGA, 2003. Estudio morfoestructural de Cuba. Geogr. Fis. Dinam. Quat., 26(1): 49-70.

GORSHKOV, A.I., I.V. KUZNETSOV, G.F. PANZA \& A.A. SOLOVIEV, 2000. Identification of future earthquake sources in the Carpatho-Balkan orogenic belt using morphostructural criteria. Pure appl. geophys., 157: 79-95.

GRÜNTHAL， G., V. SCHENK, A. ZEMAN \& Z. SCHENKOVÁ, 1990. Seismotectonic model for the earthquakes swarm of 1958/86 in the Vogtland/West Bohemian focal area. Tectonophysics, 174: 369-383.

HERNÁNDEZ, J.R., R. GONZÁLEZ \& F. ARTEAGA, 1989. Diferenciación estructuro-geomorfológica de la zona de sutura de la microplaca cubana con la placa Caribe. Editorial Academia, La Habana, 48 pp.
HERNÁNDEZ, J.R., D.A. LILIENBERG \& R. GONZÁLEZ, 1986. Regionalización morfoestructural de la Sierra Maestra y de las depresiones circundantes. Revista Ciencias de la Tierra y del Espacio, 22: 36-48.

HERNÁNDEZ, J.R., J.L. DÍAZ, A.R. MAGAZ \& A. PORTELA, 1990. Principales tipos morfoestructuro-geodinámicos de las zonas sismogeneradoras del territorio provincial de Guantánamo, Cuba. Revista Ciencias de la Tierra y del Espacio, 18: 24-32.

HERNÁNDEZ, J.R., J.L. DÍAZ, A.R. MAGAZ \& D.A. LILIENBERG, 1991. Evidencias morfoestructuro-geodinámicas del desplazamiento lateral siniestro de la zona de sutura interplacas de Bartlett. En: Morfotectónica de Cuba Oriental, La Habana, 5-9 pp.

IONIN, A.S., A. PAVLIDIS \& O. AVELIO SUÁREZ, 1977. Geología de la plataforma de Cuba. Editorial Nauka, Moscú, 215 pp.

ITURRALDE M.A., 2013. Tipología y evolución de las zonas costeras de Cuba. En: V Convención Cubana de Ciencias de la Tierra, La Habana, 1-18 pp.

ITURRALDE, M.A., 1977. Los movimientos tectónicos de la etapa de desarrollo platafórmico de Cuba. Informe científico-técnico, 20, 24 p., Academia de Ciencias de Cuba.

\section{KARTASHOV, I.P., A.G. CHERNYAHOVSKIY \& L.L. PEÑALVER, 1981. Estratigrafía de los depósitos Plioceno-Cuaternarios de Cuba. Editorial Nauka, 145 pp., Moscú.}

LEROY, S., A. MAUFFRET, P. PATRIAT \& B. MERCIER DE LÈPINAY, 2000. An alternative interpretation of the Cayman trough evolution from a reidentification of magnetic anomalies. Geophys. J. Int., 141: 539-557. 
LINARES, E., A.V. DOVBNIA, P.G. OSADCHIY, C.M. JUDOLEY, S. GIL, D. GARCÍA, A. ZUAZO, G. FURRAZOLA, A. BRITO, Y.B. EVDOKIMOV, B.A. MARKOVSKIY, V.A. TROFIMOV \& A.L. VTULOCHKIN, 1986. Mapa geológico de la República de Cuba, escala 1:500.000. Centro de Investigaciones Geológicas, Ministerio de la Industria Básica.

MAKAROV, V.I., 1987. Recent tectonics of eastern Cuba. Part 2. The Sierra Maestra-Baracoa orogenic system. General conclusions. Geotectonics, 21(2): 169-174.

MAKAROV, V.I., 1986. The neotectonics of eastern Cuba. Part one. General description. Northern and Central districts. Geotectonics, 20(6): 515-523.

MAKAROV, V.I. \& F. FORMELL, 1989. Mapa neotectónico de Cuba, escala 1:250.000. En: Mapa Tectónico de Cuba, escala 1:500.000. Academia de Ciencias de Cuba.

MANN, P. \& K. BURKE, 1984. Neotectonics of the Caribbean. Rev. Geophys. Space Phys., 22: 309-362.

MANN, P. \& K. BURKE, 1980. Neogene wrench tectonic in the Wagwater Belt, Jamaica. Pre. Trans. $9^{\text {a }}$ Conferencia de Geología del Caribe, Santo Domingo, VI, 95-97 pp.

MANN, P., F.W. TAYLOR, E. LAWRENCE \& K.U. TEH-LUNG, 1995. Actively evolving microplate formation by oblique collision and sideways motion along strike-slip faults. An example from the northeastern Caribbean plate margin. Tectonophysics, 246: 1-69.

MIRZOEV, K.M., A. BABAEV, B. GONZÁLEZ, H. ÁlVAREZ, T. CHUY, ET AL., 1989. Información de la peligrosidad sísmica de Cuba Oriental. En: Archivo de la Central Electronuclear de Holguín, Tomo I, Vol. 9, Investigaciones sismológicas.
MOLNAR, P. \& L. SYKES, 1969. Tectonics of the Caribbean and Middle America regions from focal mechanism and seismicity. Geol. Soc. Amer. Bull., 80:1, 639-1.684.

MORENO TOIRÁN, B., 2002. The new Cuban seismograph network. Seism. Res. Lett., 33(4): 504-517.

MORENO, B., M. GRANDISON \& K. ATAKAN, 2002. Crustal velocity model along the southern Cuban margin: Implications for the tectonic regime at an active plate boundary. Geophys. J. Int., 151: 632-645.

MOSSAKOVSKIY, A.A., Y.U. PUSHAROVSKI, G.E. NEKRASOV, S.P. SOKOLOV, F. FORMELL, R. CABRERA, M. ITURRALDE, ET AL., 1989. Mapa tectónico de Cuba, escala 1:500.000. Instituto de Geología y Paleontología, Academia de Ciencias de Cuba.

NÚÑEZ CAMBRA, K., 2001. La influencia de la falla Oriente en la estructura geológica del área de San Antonio del Sur, Cuba. En: IV Congreso de Geología y Minería, Geología Regional, 67-75.

OLIVA, GUTIÉRREZ G., 1989. Mapa de anomalías de Bouguer, escala 1:1.000.000. En: Nuevo Atlas Nacional de Cuba, II Características Geofísicas, II.3.4 Gravimetría.

ORBERA, L., 1980. Informe sobre las condiciones sismotectónicas de las provincias orientales para la ubicación de la CEN del norte de Holguín. Fondos de la Empresa Integral de Proyectos de la Industria Básica, 35 pp.

PÉREZ, C., 1989. Mapa de alineamientos. En: Nuevo Atlas Nacional de Cuba, III Constitución Geológica, III.3.1. 
POEY, A., 1857. Catalogue Chronologique des Tremblements de Terre Ressentis dan les Indes Occidenteles de 1530 á 1857, Accompagné d'une Revue Bibliographique Contenant Tous les Travaux Relatife aux Tremblements de Terre des Antilles. Annuarie de la Societé Météorologique de France, tomo 5, 75-227 p., Paris.

POEY, A., 1855A. Tableau Chronologique des Tremblements de Terre Ressentis a I'ile de Cuba de 1551 á 1855. Annales des Voyages, $6^{\text {a }}$ serie, tomo 11,301 p. MalteBrun, Paris.

POEY, A., 1855B. Supplément au Tableau Chronologique des Tremblements de Terre Ressentis a I'ile de Cuba de 1530 á 1855. Annales des Voyages, tomo 4, 286 p. MalteBrun, Paris.

PUBELLIER, M., MAUFFRET A., LEROY, S., VILA, J.M. \& AMILCAR, H., 2000. Plate boundary readjustment in oblique convergence: Example of the Neogene of Hispaniola, Greater Antilles. Tectonics, 19(4): 630-648.

PUSHAROVSKI, Y.U., 1988. Mapa geológico de la República de Cuba, escala 1:250.000. Academias de Ciencias de la URSS y Cuba.

PRENTICE, C.S., MANN, P., CRONE, A.J., GOLDE, R.D., HUDMUT, K.W., BRIGGS, R.W, KOELER, R.D. \& JEAN, P., 2010. Seismic hazard of the EnriquilloPlantain Garden fault in Haiti inferred from paleoseismology. Nature Geoscience, 3, doi:10.1038/NE0991.

PROL, J., G. ARIAZA \& R. OTERO, 1993. Sobre la confección de los mapas de profundidad del basamento y espesor de la corteza terrestre en el territorio cubano. Informe Científico-Técnico de la Empresa Nacional de Geofísica, Ministerio de la Industria Básica de Cuba, 36 p.
QUINTAS, F. \& J. BLANCO, 1993. Paleogeografía de la cuenca San Luis y su importancia para la interpretación de la evolución geológica de Cuba Oriental. Revista Minería y Geología, 10: 3-14.

QUINTAS, F., M. HERNÁNDEZ \& M. CAMPOS, 1994. Asociaciones estructuroformacionales del Mesozoico de Cuba Oriental y La Española. Revista Minería y Geología, 11: 3-10.

RAMÍREZ, E. \& M. SOSA, 1989. Mapa de costas. En: Nuevo Atlas Nacional de Cuba, IV Relieve, IV.3.4.

RANTSMAN, E.YA., 1979. Sites of earthquakes and morphostructures of mountain countries. Editorial Nauka, Moscú, 171 p.

RIEDEL, W., 1929. Zur Mechanik Geologisher Bruscherschei. Nungen Centr. bl. Min., Abt. B, 354-368.

RIVERA, L. \& A. CISTERNAS, 1990. Stress tensor and fault plane solutions for a population of earthquakes. Bull. Seism. Soc. Am., 80(3): 600-614.

RODRÍGUEZ INFANTE, A., M. MUNDI BOUT \& J.L. CASTILLO GONZÁLEZ, 1996. Morfotectónica y sismotectónica de la región de Moa. Revista Minería y Geología, 13(2): 13-16.

RODRÍGUEZ INFANTE, A., N.M. CARRALERO CASTRO \& M. CONDE RODRÍGUEZ, 2000. Estudio de las estructuras sismogeneradoras Quesigua y El Medio, al este de la ciudad de Moa. Revista Minería y Geología, 17(3-4): 87-90.

ROJAS-AGRAMONTE, Y., F. NEUBAUER, R. HANDLER, D.E. GARCÍA-DELGADO, G. FRIEDL \& R. DELGADO-DAMAS, 2005. Variation of paleostress patterns along the Oriente transform wrench corridor, Cuba: significance for Neogene-Quaternary 
tectonics of the Caribbean realm. Tectonophysics, 396: 161-180.

ROSENCRATZ, E. \& P. MANN, 1991. Sea MARC II mapping of transform faults in the Cayman trough, Caribbean Sea. Geology, 19: 690-693.

RUBIO,M., M.COTILLA\&L.ÁLVAREZ, 1994. Evidencias sobre la microplaca Gonave. Informe científico-técnico. En: Archivo del Departamento de Sismología, Instituto de Geofísica y Astronomía, Academia de Ciencias de Cuba, 20 p.

SHANTZER, E.V., O.M. PETROV \& G.F. FRANCO, 1976. Sobre las terrazas marinas costeras y los depósitos relacionados con ellas. En: Acumulación de sedimentos cuaternarios y formación del relieve, Editorial Nauka, Moscú, 34-80 pp.

SHEIN, V.S., V.N. SMIRNOV, K.A. KLESHOV \& L. ORBERA, 1975. Esquema neotectónico de Cuba y su plataforma marina, escala 1:1.000.000. Informe científico-técnico, Ministerio de Geología y Minería de Cuba.

SHEIN, V.S., R. TENREYRO \& E. GARCÍA, 1985A. Modelo de la constitución geológica profunda de Cuba. Serie Geológica, 1: 78-88.

SHEIN, V.S., K.A. KLISHOV, V.E. JAIN, G.E. DIKENSHTEIN, P.J. YPARRAGUIRRE \& R. RODRÍGUEZ, 1985B. Mapa tectónico de Cuba, escala 1:500.000. Centro de Investigaciones Geológicas, Ministerio de la Industria Básica.

SHERBAKOVA, B.E., V.G. BOVENKO, T.N. LUZENKO, I.P. MIROSCHINICHENKO, G.V. POZNIAKOVA \& N.I. ZHARINOVA, 1977. Informe sobre los resultados de observaciones con los aparatos "Tierra" en el territorio de Cuba Oriental, realizados en 1974-1975. Archivo del Instituto de Física de la Tierra, Vol. 1, Moscú.
SOLOVIEV, O.N., S. SIDOREV \& V.I. KOLESOVA, 1989. Mapa del campo anómalo total, escala 1:1.000.000. En: Nuevo Atlas Nacional de Cuba, II Características Geofísicas, II.2.2-3 Geomagnetismo.

SYKES, L.R. \& M. EWING, 1965. The seismicity of the Caribbean region. J. Geophys. Res., 70: 5065-5074.

TABER, S., 1922. The seismic belt in the Greater Antilles. Bull. Seism. Soc. Am., 12(4): 199-219.

TRIFONOV, V.G., F. FORMELL, J. ORO \& C. PÉREZ, 1981. Mapa de elementos estructurales de la provincia de Oriente. En: Archivo del Instituto de Geología y Paleontología, Academia de Ciencias de Cuba.

VAN BENTHEN, S. \& R. GOVERS, 2010. The Caribbean plate: pulled, pushed, or dragged? J. Geophy. Res., 115, B10409.

VAN DUSEN, S.R. \& D.I. DOSER, 2000. Faulting process of historic (1917-1962) $\mathrm{M} \geq 6.0$ earthquake along the North-Central Caribbean margin. Pure appl. geophys., 157: 719-736.

ZAPATA BALANQUÉ, J.A., 2008. Determinación de los parámetros del régimen sísmico de Cuba Oriental, de 1998 a 2007. I + D, 7(2): 19-25.

ZHIDKOV, M.P., I.M. ROTVAIN \& A.M. SADOVSKIY, 1975. Pronóstico sobre las áreas más probables de ocurrencia de los terremotos más fuertes, IV. Papers of Seismology, 8: 53-70. 